\title{
Modeling and Analysis of Mistuned Bladed Disk Vibration: Status and Emerging Directions
}

\author{
Matthew P. Castanier \\ University of Michigan, Ann Arbor, Michigan 48109-2125 \\ and \\ Christophe Pierre \\ McGill University, Montreal, Québec H3A 2K6, Canada
}

\begin{abstract}
The literature on reduced-order modeling, simulation, and analysis of the vibration of bladed disks found in gas-turbine engines is reviewed. Applications to system identification and design are also considered. In selectively surveying the literature, an emphasis is placed on key developments in the last decade that have enabled better prediction and understanding of the forced response of mistuned bladed disks, especially with respect to assessing and mitigating the harmful impact of mistuning on blade vibration, stress increases, and attendant high cycle fatigue. Important developments and emerging directions in this research area are highlighted.
\end{abstract}

\section{Introduction}

$\mathbf{T}$ URBINE engine rotors, or bladed disks, are rich dynamical systems that are known to suffer from severe vibration problems. Although a bladed disk is typically designed to have identical blades, there are always random deviations among the blades caused by manufacturing tolerances, wear, and other causes. This is called mistuning. Even though mistuning is typically small (e.g., blade natural frequency differences on the order of a few percent of the nominal values), mistuned bladed disks can have drastically larger forced response levels than the ideal, tuned design. The attendant increase in stresses can lead to premature high cycle fatigue (HCF) of the blades. HCF is a major cost, safety, and reliability issue for gas-turbine engines. For example, in 1998 it was estimated by the U.S. Air Force that about $55 \%$ of fighter jet engine safety Class A mishaps (over \$1 million in damage or loss of aircraft) and $30 \%$ of all jet engine maintenance costs were due to $\mathrm{HCF}^{1}$ It is clearly of great interest to be able to predict - and, ultimately, to reduce- the maximum blade response as a result of mistuning. The comprehensive modeling, analysis, and understanding of bladed disk vibration is thus critical to reducing the occurrence of HCF and improving the performance and reliability of turbine engines.

Bladed disk vibration first received significant attention from the research community in the late 1960s and the 1970s. Notable early work was done by Whitehead, ${ }^{2}$ Wagner, ${ }^{3}$ Dye and Henry, ${ }^{4}$ and Ewins. ${ }^{5-8}$ The bladed disk vibration literature has been surveyed by Srinivasan ${ }^{9,10}$ and Slater et al. ${ }^{11}$ The 1997 survey by Srinivasan ${ }^{10}$ was broad in scope and rich in insight, and it provides a more global view of the research issues for bladed disks. The 1999 survey by Slater et al. ${ }^{11}$ focused on forced response of bladed disks and covered many of the latest advances at that time. However, many important research developments have occurred since then, particularly with respect to finite element-based reduced-order modeling.

In this paper, the literature on bladed disk vibration is selectively surveyed, with an emphasis on key developments in the last decade that have enabled better prediction and understanding of the forced response of mistuned bladed disks. In addition, various modeling and analysis topics of recent and emerging interest are highlighted. In Sec. II, background material on the vibration of tuned and mistuned bladed disks is covered. In Sec. III, some fundamental issues for bladed disk vibration are reviewed briefly. In Sec. IV, finiteelement-based reduced-order modeling techniques are surveyed, and emerging research topics are noted. In Sec. V, key issues with respect to analysis and assessment of mistuning sensitivity are discussed. In Sec. VI, uncertainties inherent in bladed disk vibration modeling are noted, and it is suggested that a larger framework be pursued in the future for uncertainty and reliability analysis. Conclusions are summarized in Sec. VII.

\section{Background}

\section{A. Vibration of Individual Blades}

To describe the vibration of bladed disks, it is helpful to first consider the vibration of individual blades. For a system with inserted

Matthew P. Castanier is an Associate Research Scientist in the Department of Mechanical Engineering at the University of Michigan. He received his Ph.D. in Mechanical Engineering from the University of Michigan in 1995. His research interests are in the area of structural dynamics and vibration, including reduced-order modeling, low- to mid-frequency vibration and power flow in complex structures, localization and related phenomena in periodic or cyclic structures, and vibration of mistuned bladed disks in turbine engines.

Christophe Pierre is Dean of the Faculty of Engineering at McGill University in Montréal, where he is also Professor of Mechanical Engineering and holds the Canada Research Chair in Structural Dynamics and Vibration. He received the Diplôme d'Ingénieur from the Ecole Centrale de Paris, France in 1982, the M.S. from Princeton University in 1984, and the Ph.D. from Duke University in 1985. His research interests include vibrations, structural dynamics, and nonlinear dynamics. He has done pioneering work on mode localization in disordered periodic structures, for which he has received the 2005 Myklestad Award from the American Society of Mechanical Engineers. He currently works on reduced-order modeling of complex structures, mid-frequency dynamics, component mode synthesis, nonlinear modal analysis, and dry friction damped systems, with application to turbomachinery bladed disks and automotive body structures. He has published more than 100 journal articles and has given numerous invited lectures internationally.

Received 28 February 2005; revision received 15 August 2005; accepted for publication 25 August 2005. Copyright (C) 2005 by Matthew P. Castanier. Published by the American Institute of Aeronautics and Astronautics, Inc., with permission. Copies of this paper may be made for personal or internal use, on condition that the copier pay the $\$ 10.00$ per-copy fee to the Copyright Clearance Center, Inc., 222 Rosewood Drive, Danvers, MA 01923; include the code 0748-4658/06 \$10.00 in correspondence with the CCC. 
blades, a blade-alone finite element model could correspond to an actual blade component. However, it could also be defined by partitioning the finite element model of a bladed disk into disk and blade components. This is the typical approach for defining the blade and disk components of a one-piece bladed disk, which is called a blisk or integrally bladed rotor.

An important characteristic of bladed disk vibration is the set of blade-alone modes defined by holding the blade fixed at its interface with the disk. These are also referred to as cantilevered blade modes. There are several types of cantilevered blade modes, which are similar to the modes of a rectangular plate cantilevered at a narrow edge. These mode types include: flexural $(\mathrm{F})$ bending, torsion $(\mathrm{T})$, stripe (S) or chordwise bending, and edgewise (E) bending. The letters given in parentheses are examples of the shorthand often used for referring to these modes. For instance, the first (lowest frequency) flexural mode is denoted $1 \mathrm{~F}$, the second flexural mode is $2 \mathrm{~F}$, and so forth. These cantilevered blade modes are important because they closely resemble the blade motion in a vibrating bladed disk for blade-dominated system modes or for forced-response cases.

\section{B. Vibration of Tuned Bladed Disks}

A finite element model of a bladed disk used in an industrial gas turbine is shown in Fig. 1. In the idealized, tuned case, a bladed disk has identical blades. Defining a sector as one blade plus the corresponding segment of the disk, a tuned $N$-bladed disk is composed of $N$ identical sectors. Such a structure is said to have cyclic symmetry. By applying the appropriate phase conditions at the interfaces with adjacent sectors, then a model of just one sector is sufficient to predict the vibration of the entire cyclic structure. ${ }^{12}$ This makes it relatively inexpensive to run finite element analyses of tuned systems.

The free linear vibrations of cyclic structures have a notable characteristic: each system mode shape consists of identical motion in each sector except for a fixed sector-to-sector phase difference, which is called an interblade phase angle for bladed disks. Thus, looking at a point in the same relative location in each sector, the mode shapes are sinusoidal in the circumferential direction. For a bladed disk, this leads to nodal lines across the disk called nodal diameters, and the system modes are referred to as nodal diameter modes.

The natural frequencies calculated by finite element analysis for the industrial bladed disk are plotted as a function of the number of

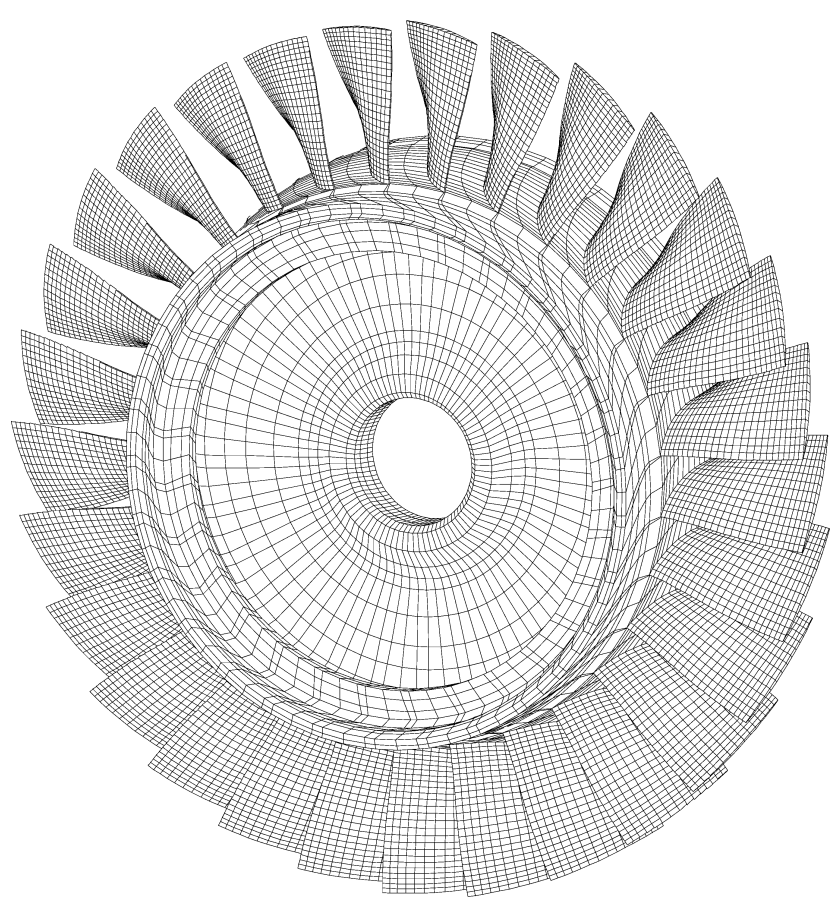

Fig. 1 Finite element mesh for an industrial bladed disk.

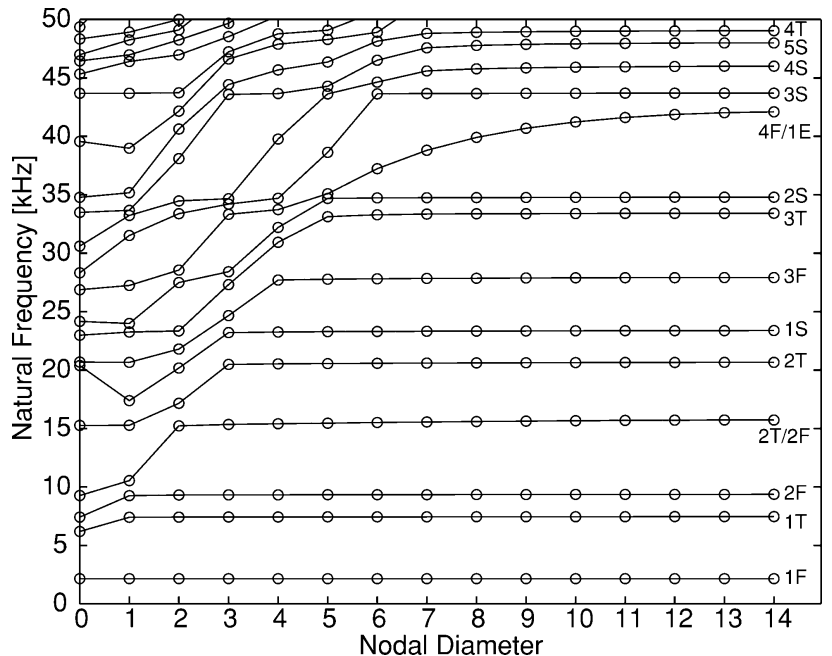

Fig. 2 Free-vibration natural frequencies vs nodal diameters for the industrial bladed disk.

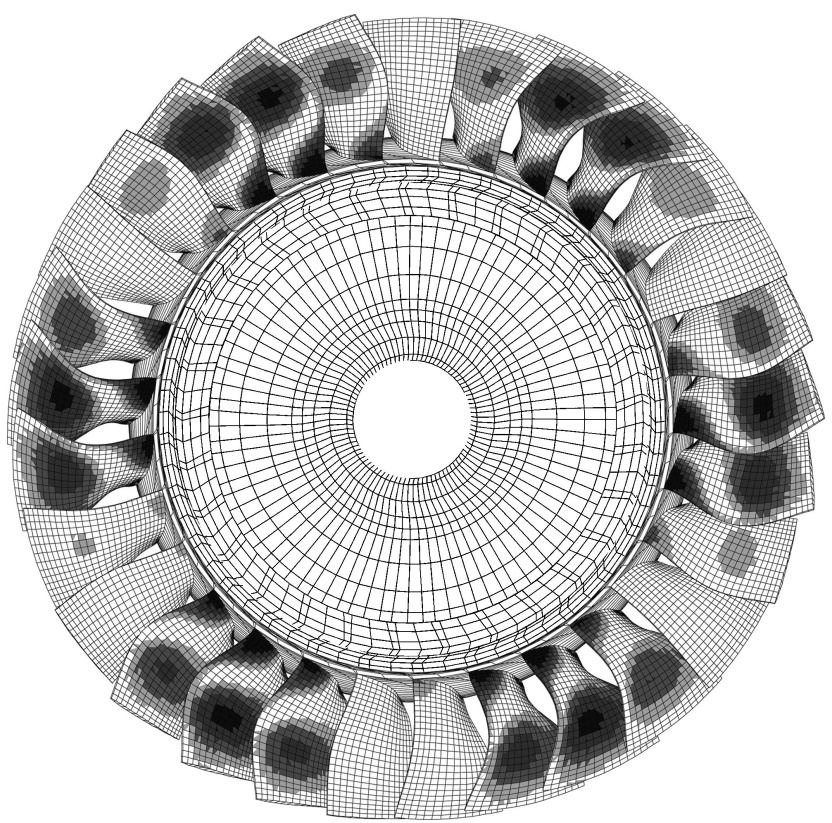

Fig. 3 Three nodal diameter-mode shape of a tuned bladed disk.

nodal diameters in Fig. 2. Lines are drawn to help visualize families of blade-dominated and disk-dominated modes. Modes dominated by blade motion tend to appear as horizontal lines in the plot, and the associated blade-alone mode is marked on the right-hand side. In contrast, the modal stiffness of a disk increases rapidly as the number of nodal diameters is increased, and so disk-dominated system modes appear as slanted lines in the plot. Note that there are several veerings between disk- and blade-dominated modes. These veering regions will be discussed in Sec. V.A.

A mode shape for the tuned system is shown in Fig. 3. This mode features three nodal diameters.

In terms of forced response, bladed disks are subject to engine order excitation. Engine order excitation is the effective traveling wave excitation that a bladed disk experiences as it passes through disturbances in the flowfield for each revolution. For example, engine order seven excitation corresponds to each blade passing through seven evenly spaced forcing peaks per revolution. This type of forcing only excites modes with a harmonic index that matches the engine order. For example, the nodal diameter three mode shown in Fig. 3 would be excited by engine order three excitation. Because there are 29 blades in the system, this mode would also be excited by engine order $26(=29-3)$, engine order $32(=29+3)$, and so forth. 


\section{Vibration of Mistuned Bladed Disks}

As just mentioned, the tuned case is an idealization. In reality, there are always small, random deviations in the blade properties because of factors such as manufacturing and material tolerances and in-operation wear. These blade-to-blade discrepancies are called mistuning. Mistuning destroys the cyclic symmetry of the system. Therefore, a single sector model can no longer be used to predict the vibration of the full system.

Blade mistuning can have a drastic effect on the vibration of a bladed disk. To illustrate this, a mode shape for the industrial bladed disk with mistuning is shown in Fig. 4. The mistuned mode shape is not a pure nodal diameter mode, but instead has multiple harmonic content so that it can be excited by all engine orders of excitation. Furthermore, the mode shape shows localization of the vibration about a few blades.

Because of the spatial confinement of vibration energy, certain blades in a mistuned system can suffer a significant increase in forced-response vibration amplitudes compared to the ideal (tuned)

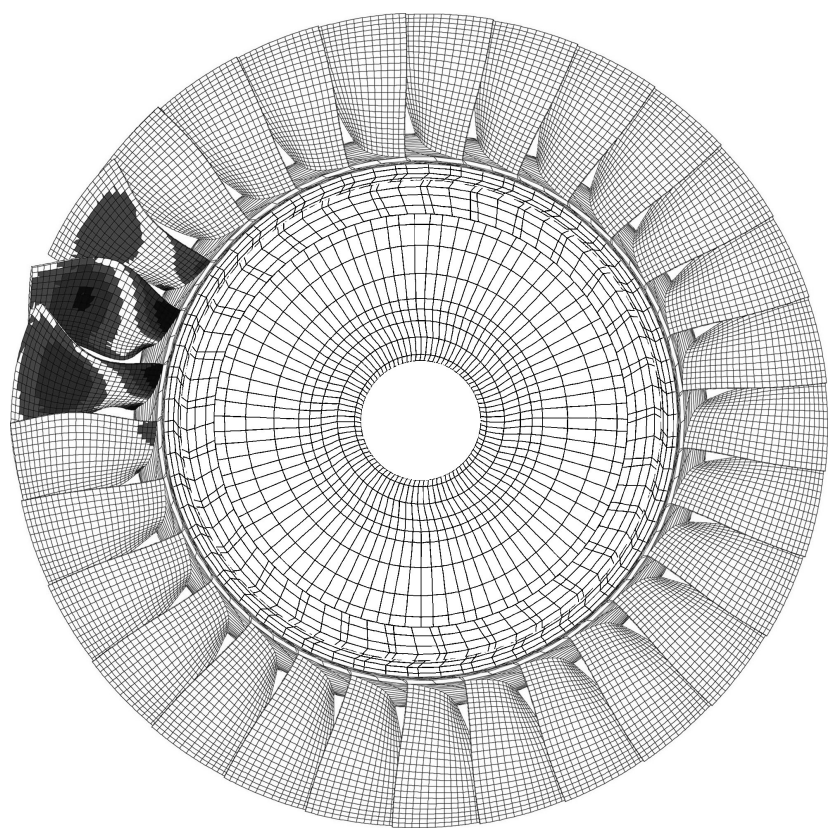

Fig. 4 Localized mode shape of a mistuned bladed disk. system. ${ }^{2,4,5,13}$ For certain operating conditions and levels of mistuning, the confinement of vibration energy to a few blades can lead to a large magnification of the maximum blade forced-response amplitude and stress. Note that the maximum blade amplitude refers to the largest resonant response for any blade in the frequency range of interest. As an example, consider the statistics of the resonant response of the industrial bladed disk of Fig. 1 in a frequency band corresponding to a single family of blade-dominated modes. Simulation results for the 99.9th-percentile amplitude magnification - the ratio of mistuned to tuned maximum blade amplitude that is expected to be exceeded by only $0.1 \%$ of the population of mistuned bladed disks-are shown in Fig. 5 for various engine orders of excitation and levels of mistuning. For some combinations of mistuning and engine order, the amplitude magnification exceeds a value of 2.5 for this system in the frequency range of interest, which corresponds to a $150 \%$ increase compared to the tuned vibration level.

\section{Fundamental Issues}

To capture the basic vibration characteristics, bladed disks have often been modeled as cyclic chains of spring-mass oscillators. The simplest such model of an $N$-sector bladed disk is a chain of $N$ single-degree-of-freedom oscillators coupled by linear springs. Additional oscillators can be added at each sector to have both blade and disk degrees of freedom (DOF). The mistuning is typically modeled as small, random perturbations to the stiffnesses of the blade DOF. Although simple, these lumped parameter models can evidence much of the rich dynamics of bladed disk systems, and they can be used for statistical investigations of mistuned forced-response characteristics (for example, see the excellent and pioneering work by Griffin and Hoosac ${ }^{14}$ ).

In this section, some fundamental issues, which were mostly investigated and explained with simple lumped parameter models, are covered. This will help illuminate the discussions in subsequent sections.

\section{A. Coupling, Disorder, and Mode Localization}

An ideal bladed disk is a cyclic structure, which is a subset of a more general class of structures called periodic structures. A periodic structure consists of a set of identical substructures that are dynamically coupled in some manner. The mode shapes of a periodic structure are characterized by sinusoidal shapes that are extended throughout the structure. However, even very slight, random perturbations to the substructures, called disorder, can have a drastic effect on the vibration of the structure. In particular, the mode shapes can become confined in a small region of the structure. This phenomenon

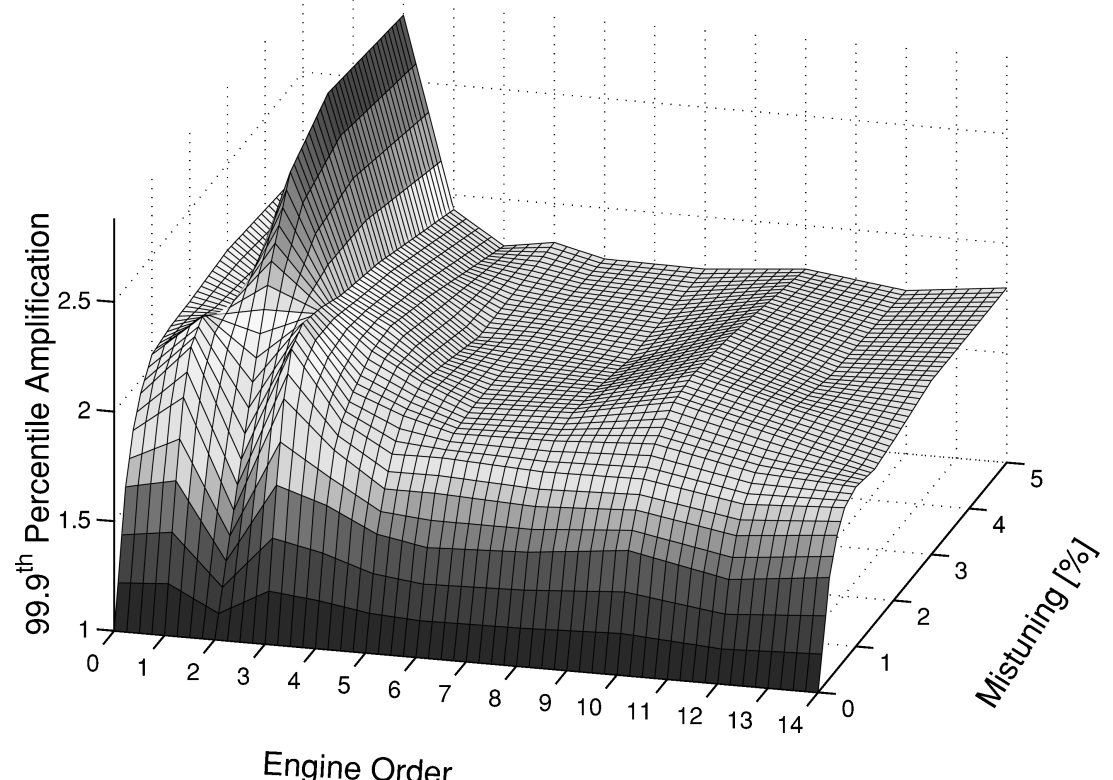

Fig. 5 The 99.9th-percentile amplitude magnification. 
is known as localization, and it was discovered by Anderson ${ }^{15}$ in the field of solid-state physics.

Although vibration localization phenomena ${ }^{16}$ had been observed in the engineering literature (for example, see the important early contributions of Ewins ${ }^{5-7}$ in bladed disk vibration), it was not recognized as Anderson localization until the work of Hodges ${ }^{17}$ in 1982. Hodges showed that mode localization increases monotonically with increasing strength of disorder or decreasing strength of mechanical coupling between substructures. That is, the degree of mode localization depends only on the disorder-to-coupling ratio.

\section{B. Interblade Coupling, Mistuning, and Forced Response Increases}

When harmonic excitation is applied to a single substructure in a disordered periodic structure, the forced-vibration response will tend to be localized around the excitation source and decay away from the source. The spatial decay rate is asymptotically exponential, and so it looks like a damped response. However, it is different from damping in that the decay is due to confinement of the energy in a small region of the structure, not dissipation. Furthermore, the localization of the vibration energy will increase with increasing disorder-to-coupling ratio. From a wave perspective, this confinement is caused by partial reflections at each connection between substructures. From a modal perspective, it is because modes localized about the source will be more strongly excited by the excitation as the mode localization increases, and modes localized away from the source will not be excited.

For bladed disks, disorder is called mistuning, and the coupling is related to the structural coupling (through the disk or shrouds) or the aerodynamic coupling between blades. Collectively, this is called interblade coupling. However, mistuned bladed disks are a notably special case of periodic structures for several reasons. First, they are cyclic structures. Second, they receive forcing from the fluid at each blade, which means that every substructure in the system is excited. Third, the excitation is engine order excitation. For an ideal, cyclic bladed disk, engine order excitation will excite only those modes with a number of nodal diameters that match the harmonic index of the excitation. For a mistuned bladed disk, the modes have multiple harmonic content, so that many modes will be excited by engine order excitation. The modes that retain significant harmonic content matching the engine order of excitation will be strongly excited.

Although mode localization increases monotonically with respect to the mistuning-to-coupling ratio, this is not true of maximum forced-response levels. It has been demonstrated that vibration amplitude magnification tends to exhibit a peak value with respect to mistuning strength or coupling strength..$^{5,18-22}$ For example, see Fig. 6, which shows the 99th, 50th, and 1st percentile amplitude magnification for the industrial bladed disk subject to engine order excitation in the frequency range of the $2 \mathrm{~F}$ modes. The 99thpercentile forced-response level increases with increasing mistuning up to a certain level, but a further increase in mistuning actually results in lower forced-response amplitudes. Using a single-DOFper-sector bladed disk model, Óttarsson and Pierre ${ }^{22}$ determined

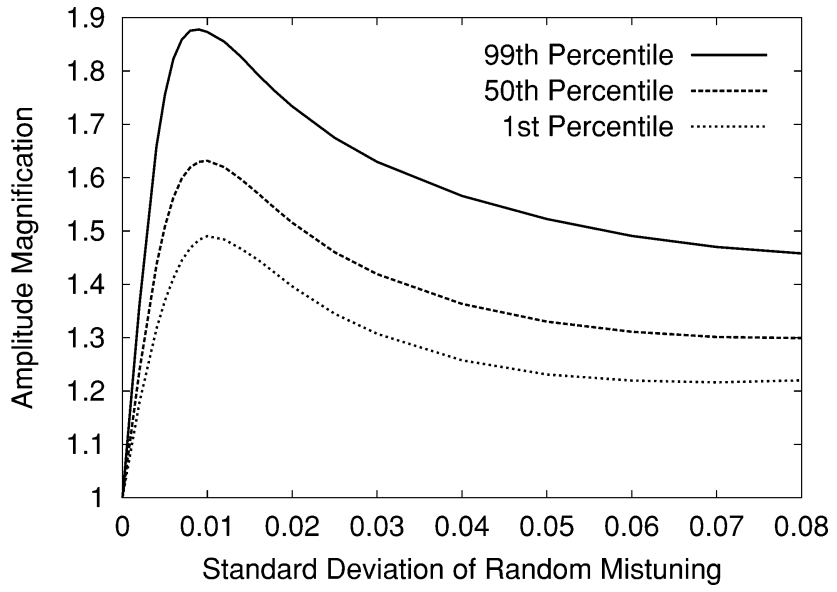

Fig. 6 Amplitude magnification as a function of mistuning strength. that this is because moderately weak interblade coupling is required for significant increases in forced-response amplitudes. Consider changes in the coupling as the mistuning level is held the same. If the interblade coupling is weak, then each blade acts as an individual mistuned oscillator, and the mistuned response does not deviate significantly from the tuned response. As coupling increases, an avenue is created for the blades to communicate vibration energy, which raises the possibility of vibration energy being transferred to and confined around certain blades. That is, vibration energy can be transferred to the maximum responding blade from other blades in the assembly, potentially resulting in great increases in forced response for some blades. Further increases in coupling allow energy to be readily exchanged among blades and eliminate the spatial confinement of vibration energy in the system, yielding tuned-like response levels for large coupling values.

In a lumped parameter model, it is straightforward to define the coupling strength and thus the mistuning-to-coupling ratio. However, it is not as simple to quantify the coupling strength for an actual bladed disk, for which interblade structural coupling depends on the relative participation of disk-dominated and blade-dominated modes in the response. This issue will be addressed in Sec. V.A.

\section{Accelerated Monte Carlo Simulation}

To estimate the statistics of the forced response for a population of randomly mistuned bladed disks with the same nominal design, a Monte Carlo simulation can be performed. First, given a value for the standard deviation of random mistuning, the mistuned blade stiffnesses for one realization of a mistuned bladed disk are assigned by a pseudo-random-number generator. Second, a frequency sweep is performed to find the largest peak response amplitude of any blade on the bladed disk. Third, this process is repeated for many realizations of mistuned rotors.

Depending on the mistuning strength and the sensitivity of the system, it can require many thousands or even tens of thousands of realizations to estimate the probability density function of the worst-case blade response, especially for capturing the tails of the distribution (e.g., the 99th percentile). Furthermore, each realization requires a frequency sweep and a search for the maximum resonant response, and it is often of interest to also sweep through many values of mistuning strength. Even using a lumped-parameter model, such a statistical analysis is computationally expensive. Therefore, Sinha and $\mathrm{Chen}^{23}$ and Mignolet and coworkers ${ }^{24-26}$ have proposed various methods for predicting the distribution of the mistuned forced response without using Monte Carlo simulations.

However, the variable of interest is the largest forced-response amplitude found for any blade in a frequency sweep. Therefore, the theory of extreme value statistics ${ }^{27,28}$ can be applied to the problem. A remarkable result from this area of probability theory is that the distribution of the maximum of a set of independently and identically distributed random trials approaches one of three extreme value distributions as the number of trials becomes large. It was shown by Castanier and Pierre ${ }^{29}$ that the distribution of the largest-responding blade amplitudes will asymptotically approach the third extreme value distribution, which is the Weibull distribution. This conclusion has also been confirmed by Mignolet et al. ${ }^{25}$

Therefore, the statistics of the mistuned forced response can be estimated by fitting the Monte Carlo results from relatively few realizations (e.g., 50 realizations) to the Weibull distribution, which reduces computational costs by orders of magnitude. This accelerated Monte Carlo simulation procedure was presented by Castanier and Pierre ${ }^{29}$ and by Bladh et al. ${ }^{30}$

The statistical results shown in Figs. 5 and 6 for the industrial bladed disk were estimated using this accelerated Monte Carlo procedure. In addition, finite element-based reduced-order modeling was used to calculate the mistuned forced response of the industrial rotor for each realization, at relatively low cost. The topic of reduced-order modeling is discussed next.

\section{Reduced-Order Modeling}

The lumped-parameter models discussed in the preceding section can be thought of as fundamental or qualitative models of 
mistuned bladed disks. For predicting the vibration response of an actual bladed disk used in a turbine engine, it is much better to take advantage of finite element models. A finite element model is typically generated for only one sector of a bladed disk. Assuming that all of the sectors are identical, cyclic symmetry routines can be used to calculate the free and forced response much more efficiently than modeling the entire system. However, not only does mistuning cause a possibly drastic change in the bladed disk dynamics, but it destroys the cyclic symmetry as well. Therefore, modeling just one sector is not sufficient; a full bladed disk model is needed. Modern industrial finite element models of a full bladed disk can be on the order of millions of degrees of freedom. Even with accelerated Monte Carlo simulation, using finite element analysis to predict the statistics of the mistuned forced response is not feasible. Therefore, reduction techniques are used to generate reduced-order models from a parent finite element model for a frequency range of interest.

\section{A. Component-Mode-Based Methods}

The first generation of finite element-based reduced-order models (ROMs) were based on component mode synthesis ${ }^{31-33}$ (CMS) or similar component-mode-based techniques. In a CMS approach, the modes of each component are calculated separately. CMS methods are referred to as fixed-interface, free-interface, or hybrid methods, depending on the boundary conditions used to calculate the component modes. Fixed-interface methods also include a set of static shapes, or constraint modes, to capture the interface motion. The CMS system model is then synthesized from the component models by enforcing compatibility conditions at the interfaces between the components. This divide-and-conquer scheme provides significant computational savings. Furthermore, for bladed disks the disk and each of the $N$ blades can be treated as separate components. This yields a system model with generalized coordinates corresponding to individual blade modes, which provides a convenient framework for modeling blade mistuning.

In 1983, the application of CMS to reduced-order modeling of bladed disk vibration was investigated by Irretier. ${ }^{34}$ Irretier employed the free-interface CMS method of Craig and Chang. ${ }^{35,36}$ He considered a 24-bladed disk and two finite element models, one with 576 DOF and the other with 1584 DOF. By selecting 15 modes for the disk and four modes for each blade, he generated a 135-DOF ROM. The free-response results from the ROM showed good agreement with those from the finite element models. In 1985, Zheng and Wang ${ }^{37}$ used free-interface CMS to model groups of blades coupled through shrouds. They found that CMS provided good accuracy with a significant reduction in computational time relative to finite element analysis. Despite the promising findings of these initial investigations, it would be almost a decade before important new contributions were made in this research area.

In 1994, Óttarsson ${ }^{38}$ made the observation that the vibration of a blade in a bladed disk could be represented with a basis of cantilevered blade modes plus a set of shapes corresponding to the blade deformation induced by the disk vibration. He suggested calculating the latter set by using finite element analysis to find the modes of the disk with massless blades attached (a bladed disk with mass density set to zero for all blade elements), which automatically defines the disk-induced static shapes for the blades. These disk-induced shapes eliminated the need to include constraint modes at the disk-blade interface, even though the blade component modes were solved with the disk-blade interface held fixed, which kept the final ROM size low. This approach also made it trivial to synthesize the full bladed disk model from the component modes because the disk "component" modes included blade motion that satisfied displacement compatibility at the disk-blade interface. Therefore, this was, in effect, a hybrid CMS technique that was tailored to modeling mistuned bladed disks. This method was presented, extended, and applied in several studies by Pierre and coworkers, ${ }^{30,39,40}$ and it was found that a ROM on the order of $10 \mathrm{~N}$ could provide good accuracy relative to the parent finite element model of an $\mathrm{N}$ bladed disk. In this same time frame, Yang and Griffin ${ }^{41}$ introduced a component-based reduced-order modeling technique that synthe- sized the disk and blade motion through an assumption of rigid-blade base motion. That is, the surface defined by the intersection of disk and blade DOF was treated as a rigid body, which also simplified the synthesis process and obviated the need to calculate constraint modes at the disk-blade interface. These methods represented a leap in predictive capabilities because they made it possible to generate reduced-order models systematically from finite element models, while generally retaining good accuracy and capturing the effects of mistuning. However, both approaches suffered from the coarse way in which the coupling at the disk-blade interface was captured. The disk-blade coupling is critically important because it relates directly to the interblade coupling, which has been shown to be a key factor for a bladed disk's sensitivity to mistuning. ${ }^{22}$

To better capture the motion at the disk-blade interface - up to the discretization of the finite element mesh-one can use the CraigBampton method ${ }^{32}$ of CMS because there is a one-to-one correspondence between Craig-Bampton constraint modes and physical finite element DOF in each interface between components. This aspect, combined with the fact that the blade modes are calculated with a fixed interface and are thus compatible with the traditional bench test measurements of blade-alone natural frequencies, makes the CraigBampton method appealing for modeling bladed disks. However, retaining all of these interface DOF for each blade renders the CMS model size large relative to a free-interface approach, especially for a fine mesh and/or a large number of blades. Nevertheless, this problem can be overcome by performing a (secondary) modal analysis on the CMS model to condense out the interface DOF ${ }^{36,42-46}$ This approach was adopted by Bladh et al., ${ }^{47,48}$ who cast the CraigBampton method into a form suitable for a bladed disk with a cyclic disk component and retrieved extremely compact ROMs (on the order of $N$ ) through the modal analysis on the intermediate CMS model. Mistuning was implemented by direct manipulation of the cantilevered blade modal properties in the CMS coordinates, and the eigenvectors for the CMS matrices were used to transform the mistuning to the final ROM coordinates. The same type of approach was also explored for modeling multistage systems. ${ }^{49}$

Another approach to CMS modeling of a bladed disk (or any cyclic structure) is to treat each sector as a separate component. This strategy has been investigated by $\operatorname{Tran}^{50}$ and Moyroud et al.. ${ }^{51}$ Tran used CMS techniques with component interface reduction to keep the system model size low. Moyroud et al. did not consider interface reduction, but they explored issues such as modeling mistuned and shrouded bladed disks. For shrouded bladed disks, they found that a sector-wise application of the classical Craig-Bampton method was an excellent approach for handling a full range of friction constraints at shroud interfaces. However, in the case of fully stuck shrouds, which is analogous to the unshrouded case in terms of modeling, they found that a modal reduction approach that had been introduced recently by Yang and Griffin ${ }^{52}$ was clearly more efficient. This approach is discussed next.

\section{B. System-Mode-Based Methods}

In 2001, Yang and Griffin ${ }^{52}$ presented an important new reducedorder modeling technique that they called the subset of nominal modes (SNM) method. Their modeling approach was based on their earlier observation that a selected set of tuned system modes provides an excellent basis for representing the vibration of mistuned bladed disks if the mistuning is slight. ${ }^{53}$ That is, the reduced-order model can be constructed with classical modal analysis by selecting a frequency range that includes a family of blade-dominated system modes, typically including at least one mode or mode pair per nodal diameter to span the space of the mistuned modes. This is essentially a simple way to provide a de facto Fourier basis for representing the vibration of the bladed disk. The mistuning is then included in the model by assuming a form of the mistuned blade structural matrices and using an appropriate coordinate transformation to express the mistuning in system modal coordinates. In light of the component-mode-based approaches covered in the preceding section, a key insight from the work of Yang and Griffin was that it was not necessary to use component modes to model a bladed disk to introduce mistuning. 
The fact that mistuned bladed disk modes are essentially linear combinations of tuned system modes had been recognized previously, and in some studies this property has been used to investigate the interpretation and implications of the harmonic content of mistuned modes. ${ }^{54,55}$ However, the SNM method was the first reducedorder modeling technique to fully exploit this idea to simply and directly generate an ROM as small as $N$ DOF for an $N$-bladed disk, which is a minimal size for representing a mistuned system. Furthermore, the ROMs generated with this method retain high accuracy relative to the parent finite element model, but at a fraction of the cost. Thus, this technique began what could be called a second generation of reduced-order modeling methods, which are generally system-mode-based methods that yield ROMs on the order of $N$ DOF.

Feiner and Griffin ${ }^{56}$ subsequently derived a simplified form of SNM for the case of an isolated family of blade-dominated modes. In their method, the only required input is a set of tuned system natural frequencies and the blade-alone frequency deviations caused by mistuning. Because of its simplicity, they called this a fundamental model of mistuning (FMM). For an example case, they found good agreement with finite element results for operating conditions that excited isolated blade-dominated modes, although the accuracy broke down near veerings of disk- and blade-dominated modes and in regions with higher modal density. Nevertheless, the minimal input requirements make it a good candidate for applications in which high fidelity is less important than the ability to obtain simple and quick estimates of mistuning effects.

Petrov et al. ${ }^{57}$ proposed an alternative approach for efficient vibration modeling of mistuned bladed disks. In their formulation, the mistuned system forced-response vector was expressed in terms of the tuned system forced-response vector and a modification matrix. The modification matrix was constructed using the frequencyresponse-function (FRF) matrix of the tuned system and a mistuning matrix defined as the perturbed part of the system dynamic stiffness matrix. They noted that it was an exact expression and that it could be solved by considering only a subset of the system DOF, referred to as active coordinates, which are DOF where mistuning is applied or where forced-response levels are of interest. This would seem to imply that all physical blade DOF might need to be retained in the model. However, they enabled the possibility of only including a few active DOF per blade by introducing socalled mistuning elements: lumped masses, dampers, and springs that are attached to selected blade DOF to represent the effects of mistuning. In addition, they calculated the tuned FRF matrix efficiently by representing the tuned model with a set of system modes. They noted that the reduced-order model in active coordinates was only as accurate as this modal representation of the tuned system. In this sense, this is a system-mode-based method, although the order reduction is achieved through the formulation based on the relationship between the tuned and mistuned forced response.

Lim et al. ${ }^{58}$ introduced a method that makes use of both tuned system modes and blade component modes to generate reducedorder models of mistuned bladed disks. As in the SNM method, ${ }^{52}$ a selected set of tuned system modes is used to form a basis for the ROM. However, for the purposes of modeling mistuning, the bladealone motion is represented by a set of cantilevered blade modes and, optionally, the Craig-Bampton constraint modes $^{32}$ for the DOF that are held fixed in the cantilevered blade model. For this reason, it is called the component mode mistuning (CMM) method. Modal participation factors are calculated to relate the blade component modes to the blade motion in the tuned system modes, and this relation is used to project the individual blade mistuning onto the ROM. This mistuning projection approach is an extension of the method developed by Bladh et al. ${ }^{40}$ for reduced-order modeling of mistuned bladed disks with shrouds. A notable feature of the CMM method is that it can handle various types of blade mistuning in a systematic manner, including nonuniform variations of individual blades that lead to different frequency mistuning patterns for different types of blade-alone modes.

\section{New Methods and Emerging Topics}

Even for the latest state-of-the-art reduced-order models, there are still several simplifying assumptions that limit their capabilities for predicting the response of actual bladed disks in turbine engines. To illustrate this, consider Fig. 1, which shows the bladed disk as it is typically modeled for structural dynamic analyses: in vacuo, and isolated from other stages. In reality, a bladed disk is usually one stage of a multistage rotor, and it is subject to the effects of the fluid flow, which provides not only excitation but also damping and interblade coupling. Nonlinear phenomena associated with various physical and design aspects of turbine engine rotors provide additional complexities. Therefore, there are still many future research challenges and opportunities. In the following subsections, some emerging topics for vibration modeling of mistuned bladed disks are highlighted.

\section{Combined Structural and Aerodynamic Coupling}

Because the interblade coupling is so crucial to the mistuning sensitivity of a bladed disk, for some systems the inclusion of the coupling through the fluid might be critical to generating a meaningful model of the mistuned response. The vibration of mistuned bladed disks with both structural and aerodynamic coupling has been examined in several studies to date..$^{59-64}$ However, recently developed reduced-order modeling methods provide a new opportunity to investigate this issue more thoroughly. Furthermore, the $\mathrm{SNM},{ }^{52} \mathrm{FMM},{ }^{56}$ and $\mathrm{CMM}^{58}$ methods all generate ROMs in tuned system modal coordinates, which allows easy incorporation of aerodynamic coupling. In fact, the CMM and SNM formulations were presented with unsteady aerodynamic terms included in the system equations of motion. New research in this area has been recently initiated by Kielb et al. ${ }^{65,66}$ using the FMM method, and He et al. ${ }^{67}$ using the CMM method.

\section{Modeling of Nonlinearities and Blade Damage}

Although the reduced-order modeling methods discussed earlier in this section were formulated for linear vibration analysis, there are many examples of important nonlinear phenomena in bladed disks. There are nonlinearities caused by contact at shroud interfaces, at dovetail attachments for inserted blades, ${ }^{68,69}$ and caused by rubbing between blade tips and the engine casing. ${ }^{70}$ There are also nonlinearities introduced by vibration reduction elements such as impact dampers ${ }^{71,72}$ and dry friction dampers.

Recently, several investigators have been developing comprehensive computational tools for the study of structural systems with strong, nonanalytic nonlinearities. For example, efficient hybrid frequency time $\mathrm{e}^{73}$ and other methods have been developed for the prediction of multiharmonic, steady-state response of bladed disks with nonlinearities. ${ }^{74-76}$ The significant advances made by various investigators for reduced-order modeling of mistuned linear systems and for nonlinear analysis enable the exploration of the physical interactive mechanisms between mistuning and nonlinearities for a bladed disk. Such investigations would yield a better understanding of the vibration of realistic (i.e., mistuned or damaged) structures as they operate in environments modeled so as to better describe realistic operating conditions (e.g., frictional boundary interfaces).

Other nonlinearities and complexities include the effects of rotation, ${ }^{77,78}$ cracked blades, and geometric blade damage (e.g., caused by a bird strike or a missing material in the blade tip). The last item is interesting in that such geometric changes to the blade result in blade-mode-shape mistuning. One consequence of this is that the number of tuned-system normal modes required to describe the mistuned-system normal modes increases dramatically, which makes it impractical to use system-mode-based methods such as $\mathrm{SNM}^{52}$ or CMM. ${ }^{58}$ To address this, a reduced-order modeling technique for bladed disks with geometric damage was recently developed by Lim et al. ${ }^{79}$ This technique employs a mode-acceleration formulation with static mode compensation to account for the effects of the geometric changes on the mode shapes. This and other specialized techniques could be combined with mistuning models 
to assess the reliability and safety of bladed disks that suffer inoperation blade damage.

\section{Multistage Modeling}

Bladed disks are typically modeled as isolated systems, but in general they are actually connected to adjacent stages in a multistage rotor. A recent study by Bladh et al. ${ }^{80}$ has shown that connecting a second stage to a single-stage finite element model of a bladed disk can lead to significant changes for predictions of the maximum blade response. For some operating conditions, dramatic changes in the first stage's sensitivity to mistuning were observed. This was explained by the presence of the adjacent stage, which alters bladeto-blade coupling through the disk and thus mistuning sensitivity. Furthermore, it was found that applying constraints to the boundary degrees of freedom of a single stage could not faithfully capture the boundary conditions of the actual stage-to-stage connection.

Therefore, it appears that multistage modeling can be essential to improving the predictive capabilities of mistuned bladed disk simulations. There are several fundamental research issues to be addressed by future research. For example, the coupling of multiple stages destroys the cyclic symmetry of the system, because of the different number of blades for each stage. This means that even tuned finite element models of the multistage assembly possess no special symmetry, which mandates the use of effective reduced-order modeling methods. In addition, the convenient nodal diameter modes of a tuned bladed disk can no longer be readily identified from singlesector analyses, because multistage systems do not possess cyclic symmetry. It is also likely that some modes will have significant strain energy in multiple stages. Thus, the characterization, identification, and classification of multistage system modes will need to be explored. Finally, the influence of the stage-to-stage connections on the mistuned forced response could potentially be used to improve the robustness of rotor designs with respect to their sensitivity to blade mistuning. This opens a new set of design possibilities that can only be exploited through the development of multistage modeling capabilities.

\section{Fundamental and Alternative Models}

The discussions in the preceding subsections have largely focused on handling complexities by incorporating new capabilities in bladed disk modeling. However, another way to handle complexity is to avoid it or to attack it from a different angle. By developing simpler frameworks or alternative formulations, new benefits and insights can be gained. An obvious example of this is the Fundamental Model of Mistuning developed by Feiner and Griffin, ${ }^{56}$ which has already been found to be readily applicable to the problem of mistuning identification (see Sec. V.C). Another example is the use of vibration power flow analysis ${ }^{81}$ to examine the exchange of vibration energy among blades..$^{22,82,83}$ Such an alternative formulation can also be used as a preprocessor (e.g., to identify operating conditions that can cause high blade forced response) or as a complement to finite element-based reduced-order models.

\section{Analysis and Assessment with Respect to Mistuning Sensitivity}

The preceding section discussed the development of reducedorder vibration modeling methods. The next logical step is to be able to apply these tools and develop additional techniques to assess and improve the bladed disk design with respect to its sensitivity to mistuning. In this section, some research issues in this area are discussed.

\section{A. Frequency Veerings and Structural Coupling}

As mentioned earlier, the increase in maximum forced response for mistuned bladed disks is caused by the transfer and significant confinement of vibration energy to a few blades. Thus, the interblade coupling plays a crucial role in the dynamics of the system because it governs the communication of vibration energy among blades.

Physically, blades are coupled through the disk, through shrouds, and through the fluid. For the unshrouded case, the structural cou- pling through the disk is typically the dominant mechanism for energy transfer. Therefore, blade-blade coupling is largely dependent on disk-blade coupling, which is related to the interaction between the disk and blade dynamics. This can be deduced, at least to a certain extent, from an examination of a plot of natural frequencies vs number of nodal diameters.

Consider the 29-blade industrial rotor shown in Fig. 1. The plot of free-vibration natural frequencies vs number of nodal diameters is shown in Fig. 2. The lines are drawn to help visualize the various families of modes. The groups of modes that appear as horizontal lines are blade-dominated modes, and the blade mode family $(1 \mathrm{~F}$, $1 \mathrm{~T}$, etc.) for each is labeled on the plot. Blade-dominated modes tend to feature little disk motion, and thus they have weak interblade coupling. The sloped lines correspond to disk-dominated modes, which have strong interblade coupling. Note that there are several regions where the disk and blade modes appear to veer away from each other. These modes in the veering regions tend to feature mixed disk-blade motion. Therefore, the blades have significant vibration response if these modes are excited, and there is also a mechanism for transferring energy between blades through the disk. ${ }^{22}$ This combination of conditions can lead to the blade vibration energy being localized in a few blades when mistuning is present, which results in high values of mistuned forced response. Therefore, the frequency veering regions are of great interest and can provide important information with respect to the system's sensitivity to mistuning.

The "curve veering" phenomenon has been studied in the field of vibration, with many applications to models of blades and turbine engine rotors, for the last three decades. ${ }^{19,20,30,38,84-106}$ This work was sparked by a 1974 article by Leissa ${ }^{84}$ in which he commented on an apparent curve veering aberration in the natural frequency loci of rectangular cantilever plates for varying aspect ratio shown in an earlier study by Claassen and Thorne. ${ }^{107}$ Leissa rather poetically described the changes in mode shapes in these veering regions as follows: “. . in the 'transition zones' of veering away the mode shapes and nodal patterns must undergo violent change-figuratively speaking, a dragonfly one instant, a butterfly the next, and something indescribable in between." Leissa questioned whether the curve veerings were real or an artifact of the discretization used to generate numerical solutions. In 1981, Kuttler and Sigilitto ${ }^{85}$ used an approximate solution method for rectangular plates that indicated that such curve veerings are indeed real. Perkins and Mote confirmed the existence of curve veerings for continuous models and established criteria for distinguishing between crossings and veerings. ${ }^{86}$

Gottlieb $^{87}$ considered the case of two pendulums coupled by a spring and examined frequency veerings as the ratio of pendulum lengths was varied. He noted that a crossing occurs only for the decoupled case, and that for coupling greater than zero there exists a curve veering. In 1988, Pierre ${ }^{88}$ considered eigenvalue loci veering for the two-pendulum system, a chain of coupled oscillators, and other models of periodic structures. He used perturbation methods to examine connections among eigenvalue loci veering, coupling, and localization. He showed that weak coupling leads to both close veerings with sharp curvature and strongly localized modes in the free response of disordered structures. That same year, Wei and Pierre ${ }^{19,20}$ investigated veerings in the free response of mistuned cyclic chains of oscillators, as a lumped-parameter representation of the vibration of bladed disks. The eigenvalue loci veering investigated for these coupled-oscillator systems occurred with respect to varying disorder or mistuning strength. Furthermore, there exists no veering with respect to varying nodal diameters until the model includes at least two DOF per sector (e.g., one disk DOF and one blade DOF).

In 1992, Afolabi and Alabi ${ }^{93}$ discussed the veering of eigenvalue loci vs number of nodal diameters for bladed disks in terms of catastrophe theory, ${ }^{108,109}$ relating the veerings to bifurcation diagrams. They noted that there is a crossing of blade and disk modes for the uncoupled case; a close, sharp veering for weak coupling between blades; and a wide, shallow veering for strong coupling. They pointed out that, in the veering region, the "forced vibration amplitudes of the individual blades are likely to change greatly under the smallest change in the system's parameters," and recommended that researchers devote more attention to these veering regions. 


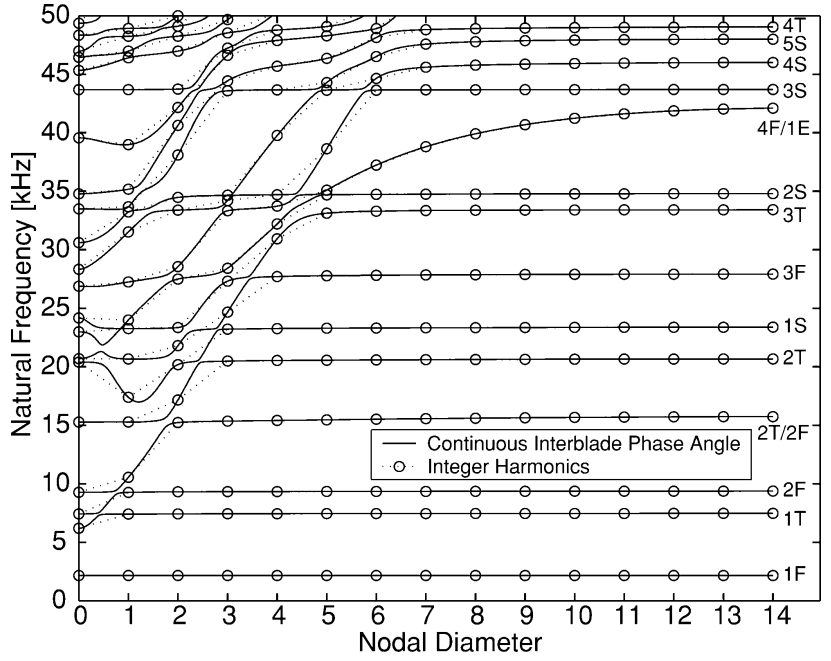

Fig. 7 Natural frequencies vs nodal diameters from the continuous interblade phase angle calculation.

To further investigate frequency veerings with respect to number of nodal diameters, a method was developed by the Bladh et al. ${ }^{30,100}$ to obtain continuous natural frequency curves. The approach taken is to consider the phase relationship between adjacent blades or the interblade phase angle. The interblade phase angle $\phi_{h}$ takes on a discrete set of values for the modes of an $N$-blade rotor:

$$
\phi_{h}=h(2 \pi / N) \quad h=0,1, \ldots, \operatorname{int}[N / 2]
$$

where $h$ is the number of nodal diameters or the harmonic number. From the preceding equation, it is seen that the interblade phase angle is a function of the ratio $h / N$. Therefore, a continuous nodal diameter mode description can be obtained either by letting $h$ assume noninteger values or, equivalently, by specifying integer values of $h$ and $N$ that yield the same ratio. Choosing the latter option, one can use cyclic symmetry solvers in commercial finite element software to compute these intermediate interblade phase angle modes, as long as the finite element code does not check for geometric consistency. For example, the frequency plot in Fig. 7 was obtained using MSC.NASTRAN by setting the number of sectors to 580 , yielding 20 data points per nodal diameter for the 29-blade rotor. Comparing this plot with Fig. 2, note that several veerings can now be seen in detail in Fig. 7 .

Although the continuous curves might seem nonphysical, it is important to recognize that the geometry of the fundamental sector remains unchanged, and thus any interblade phase angle for which the first and $N$ th sector have identical motion at their shared boundary will correspond to an actual nodal diameter mode of the original system. From this perspective, the integer nodal diameter modes are sampled values on the frequency curves of the system with an infinite number of sectors. Furthermore, veerings that are not apparent for the case of integer nodal diameters are seen in the continuous veering plot, and it is then possible to better determine whether the actual nodal diameter modes are disk dominated (sloped part of a curve), blade dominated (flat part of a curve), or mixed (near center of veering). Thus, quantifying the veering characteristics and determining the proximity of the nodal diameters to these veerings can yield key information for quantifying blade-to-blade coupling strength and predicting mistuning sensitivity. ${ }^{30,103}$

Certainly the prospect of using tuned free-response information to make rapid predictions regarding mistuned forced response and mistuning sensitivity is a tantalizing prospect. Not surprisingly, this has received significant attention in the literature in recent years. ${ }^{30,102,103,105,106}$ Geometric characteristics of veering regions can also be used to identify representative lumped-parameter models with two or more DOF per sector. ${ }^{102,105}$ These models typically capture vibration characteristics in the frequency range around a family of blade-dominated modes, and the systematic identification of their parameters opens the door for applying fundamental analy- sis techniques that were developed for simple models of disordered periodic and cyclic structures during the last few decades.

Another aspect of the importance of blade-to-blade coupling through the disk is that it is possible to influence the blade response, including the sensitivity to mistuning, through variation of the disk design parameters. Slater and Blair ${ }^{110}$ investigated this strategy by examining the effect of small disk design modifications on mode localization in a simple finite element model of a bladed disk. Bladh et al. ${ }^{80}$ also used finite element analysis for a simple finite element model to consider the influence of both multistage coupling and changes in nominal disk stiffness on natural frequency veerings and mistuning sensitivity. In general, though, this topic has received surprisingly little attention to date in bladed disk vibration research.

\section{B. Mistuning Patterns and Intentional Mistuning}

When considering the forced-response statistics for a population of randomly mistuned bladed disks, there is often a large range of forced-response levels. This is true even when focusing on the largest responding blade for any blade in the system, or the extreme value statistics. Consider the results shown in Fig. 6, which show selected percentiles of the vibration amplitude magnification caused by mistuning. There is a significant gap between the 99th and first percentiles. Clearly, the particular pattern of the mistuning has a large effect on the forced-response amplification, even for small mistuning.

It is natural to wonder what sort of mistuning patterns lead to high or low responses. In fact, there have been several studies on using optimization methods to find the worst or best overall mistuning patterns in terms of aeroelastic stability ${ }^{111-114}$ or forced -response amplification. ${ }^{115-118}$ There have also been studies on finding the best blade arrangement when a set of mistuned blades are given, ${ }^{119,120}$ although interest in this strategy is likely to decrease as the turbine engine industry moves away from manufacturing bladed disks with inserted blades and toward single-piece, integrally bladed designs.

Finding the worst-case mistuning pattern is useful because it involves finding the maximum blade forced response for the entire population of mistuned bladed disks. This provides a measure of the mistuning sensitivity and the reliability of the nominal bladed disk design. Furthermore, investigating the types of mistuning patterns that lead to high response, and their effect on system vibration characteristics such as mode shapes, can provide important insight.

The best-case mistuning pattern is of interest, of course, because it minimizes the forced-response level. However, the best-case mistuning pattern does not necessarily represent an optimal or nearoptimal design because the actual response can be greatly affected by the additional, random mistuning that will inevitably occur in the manufacturing process or during engine operation. In fact, Crawley and Hall ${ }^{111}$ showed that the performance of the optimal pattern could be very sensitive to small changes in the mistuning values.

The heart of the design challenge, then, is to determine a mistuning pattern that can be implemented in the nominal design that will make the system less sensitive to random mistuning. This is usually referred to as intentional mistuning. Intentional mistuning is a design strategy that is appealing from many viewpoints. First, because structures with cyclic symmetry can be so sensitive to small mistuning, it makes sense to move away from a design with identical sectors. Second, the amplitude magnification often exhibits a peak with respect to mistuning strength at a small value of mistuning, as seen in Fig. 6. This suggests that it might be best to start with sufficient mistuning to put the nominal design point on the other side of the peak. Third, mistuning tends to increase the stability of a rotor with respect to flutter, ${ }^{16,59,111}$ which means that intentional mistuning can have multiple benefits for increasing the safety of a design.

Intentional mistuning as a design strategy seems to have been first considered, either directly or indirectly, in a few studies performed 20-30 years ago. In 1975, El-Bayoumy and Srinivasan ${ }^{121}$ investigated the effect on the system mode shapes and forced response of having two distinct blade types, as defined by two different nominal natural frequencies, arranged in various patterns around the disk. However, they did not consider additional random mistuning. In 1980 Ewins $^{122}$ discussed the possible advantages of bladed disk 
designs in which blades are grouped into "packets" of shrouded blades. This type of design introduces a special form of mistuning, and Ewins explored the beneficial effects of "detuning" the response of certain modes. The vibration modes of packeted bladed disks were investigated further by Ewins and Imregun, ${ }^{123}$ using both computational and experimental methods.

In 1984, Griffin and Hoosac ${ }^{14}$ conducted what appears to be the first research investigation into the effectiveness of using intentional mistuning in the design of a randomly mistuned bladed disk. They investigated the case of two blade types placed in alternating slots around the disk. They implemented this mistuning by setting the mean weights of the two blade types to be $20 \%$ apart $( \pm 10 \%$ of the original weight). From Monte Carlo simulations with and without intentional mistuning, they found that this "alternate mistuning" pattern reduced the worst-case blade amplitude significantly. In 1985, Crawley and Hall ${ }^{111}$ also considered intentional mistuning, as well as random mistuning, and they even found optimal patterns of intentional mistuning. However, the focus of their work was the aerodynamic stability (flutter) of the rotor.

More recently, Rzadkowski ${ }^{124}$ investigated the transient nozzle excitation of mistuned bladed disks. By examining several configurations of a set of nominally different blades, Rządkowski found that a random configuration led to the greatest increase in stresses, whereas a periodic (harmonic) blade arrangement was the best distribution in terms of minimizing the largest stresses. Yiu and Ewins ${ }^{119}$ simulated many randomly mistuned realizations of a simple model of a 36-bladed disk, and they used discrete Fourier transforms to find the harmonic components of the best and worst mistuning patterns. However, they did not include intentional mistuning in the design.

In 1997, new research into the use of intentional mistuning was initiated by the work of Castanier and Pierre. ${ }^{29}$ In this and subsequent studies, ${ }^{54,55,125}$ they investigated the effect of introducing intentional mistuning into the nominal design of a rotor. To examine a range of designs, harmonic patterns of intentional mistuning were considered. In addition, square-wave patterns of intentional mistuning, which only require two different blade types, were proposed as a more practical design alternative. For all of the designs, the effect of random mistuning on the statistics of the maximum blade forcedresponse amplitudes were investigated. It was found that certain patterns of intentional mistuning were very effective in reducing the maximum vibration levels. Furthermore, for effective patterns of intentional mistuning the vibration level was relatively flat with respect to the random mistuning level, indicating a decrease in sensitivity to random mistuning. In general, it was found that intentional mistuning made the rotor design much more robust with respect to random mistuning.

The degree of mode localization and the harmonic content (Fourier decomposition) of the mode shapes were also considered for both the original design and designs with intentional mistuning. ${ }^{54,55}$ For the original design, it was found that the worstcase response occurs at a resonant frequency for which the corresponding mode: 1) exhibits some moderate degree of localization and 2) has a strong nodal diameter component that matches the engine order of the forcing. (This same phenomenon was later observed by Kenyon et al., ${ }^{126}$ who referred to the critical mode shape changes as mode distortion.) By adding intentional mistuning to the design, the modes became more localized. However, the dominant nodal diameter components of the modes were eliminated, making the system less susceptible to being strongly excited by engine order excitation.

In the last few years, there have been several studies on determining effective patterns of intentional mistuning and/or mistuning patterns that lead to high or low response levels. ${ }^{82,117,118,120,127-134}$ Kenyon and Griffin ${ }^{128}$ analyzed the effect of harmonic mistuning on a rotor's sensitivity to small perturbations in the mistuning. Jones and O'Hara ${ }^{130}$ found that a linear pattern (one period of a sawtooth-wave pattern) of intentional mistuning was very effective. Choi et al. ${ }^{131}$ and Hou and Cross ${ }^{134}$ considered the optimization of intentional mistuning patterns in order to reduce forced response amplitudes. Lim et al. ${ }^{82}$ proposed some rules for reducing the design space for intentional mistuning, so that a small set of promising intentional mistuning patterns can be identified without requiring a full optimization process. The effectiveness of intentional mistuning has also been validated experimentally in recent studies for the case of a square-wave pattern ${ }^{135}$ and a linear pattern. ${ }^{130}$

\section{Mistuning Identification}

An important practical consideration for bladed disk vibration research is how to identify the mistuning that is actually present in a manufactured bladed disk. For rotor stages with inserted blades, the blade-alone natural frequencies can be measured directly to determine mistuning values to be used in simulations as well as to estimate mistuned blade structural dynamic properties. ${ }^{136-138}$ However, for an integrally bladed disk-a one-piece bladed disk-the blades cannot be removed from the assembly. Therefore, mistuning identification techniques based on experimental measurements of system response have been developed recently to determine the individual blade mistuning pattern for each blade-dominated mode family of interest.

The first such mistuning identification technique was developed by Judge et al. ${ }^{139-141}$ To identify individual blade mistuning from the vibration response of an entire bladed disk two sources of information were used: a finite element model of the bladed disk and a set a measurements of the response of the actual bladed disk. To formulate the identification algorithm, an adapted form of the CMS-based reduced-order modeling technique developed by Bladh et al. ${ }^{47}$ was employed. In the mistuning identification process, secondary modal analysis was used to condense out only the disk and disk-blade interface portions of the CMS model. This yielded an extremely reduced model that retained blade modal stiffnesses explicitly. Then a small set of experimental measurements of the system response was used to determine the mistuning for the isolated blade modal stiffnesses. Either mode shape measurements or forced-response measurements can be used. ${ }^{141}$ Similar techniques have recently been developed by Feiner and Griffin ${ }^{142,143}$ based on the FMM method and Lim and coworkers ${ }^{144,145}$ based on the CMM method. The technique of Lim et al. also incorporated a reduced-order model updating procedure to improve the accuracy of the identification procedure.

Mistuning identification can also be used to assess the quality of the manufacturing process, to flag possible tooling problems, ${ }^{143}$ and to perform structural health monitoring of turbine engine rotors. An example of the last item is to identify a cracked blade. Cracks or other types of blade damage can have very small effects on the blade-alone frequencies yet still cause strong changes in some of the system mode shapes. ${ }^{79}$ Therefore, these system-responsebased identification methods are promising for damage detection applications.

\section{Uncertainty and Reliability Analysis}

Because blade mistuning is random, most forced-response analyses of bladed disks are probabilistic. However, mistuning is not the only form of uncertainty in the system. Certainly, the research topics discussed in Sec. IV.C are examples of phenomena that could potentially be of great importance to the mistuned blade response but are often neglected in vibration models. Thus, modeling assumptions and limitations introduce significant uncertainty for forced-response predictions. Moreover, even when some aspect of the dynamics is well modeled, certain parameter values might not be precisely known. This is yet another form of uncertainty. An example is the estimation of mistuning values used for the blades of a particular rotor stage. ${ }^{141,146}$

In general, the modeling and computational tools developed to date would be enhanced by incorporating fundamental analysis of the propagation of uncertainty into free- and forced-response predictions. That is, researchers developing vibration analysis methods should attempt to account for the sensitivity of the mistuned response predictions to various types of parameter uncertainties and modeling assumptions, such as 1) the nominal system parameters used in the model (tuned blade-alone natural frequencies, assumed damping coefficients, etc.); 2) boundary conditions imposed at the stage-tostage connections of a bladed disk; 3 ) the relative strength of aerodynamic and structural coupling, or the implications of neglecting 
aerodynamic coupling; and 4) other types of mistuning besides traditional blade frequency or modal stiffness mistuning, such as forcing mistuning (i.e., perturbations about pure engine order excitations), geometric blade mistuning, damping mistuning, ${ }^{147}$ blade stagger angle mistuning, ${ }^{142,148}$ and disk mistuning. One key contribution of this uncertainty analysis would be a capability for assigning confidence limits to numerical simulation results for mistuned systems. Another contribution would be a framework for determining the relative importance of neglected phenomena and thereby choosing a level of modeling fidelity that is commensurate with the goals of the simulation. In some cases, it might be found that a simpler model can provide sufficiently useful predictions for, say, a design sensitivity study, and that a more complex model would not be worth the additional computational expense given unavoidable modeling limitations and uncertainties.

Finally, it would be interesting to investigate the use of reliability methods developed in other disciplines to applications in vibration analysis of mistuned bladed disks. This poses great challenges because bladed disks are highly sensitive to small parameter changes and the blade response varies nonlinearly with respect to the parameter space. It might turn out that accelerated Monte Carlo simulation is the best option for characterizing the statistics and bounds of the mistuned forced response. On the other hand, the variety of vibration modeling and analysis tools that have been developed to date provide a wealth of opportunity for exploring new methods for assessing and improving the reliability and robustness of turbine engine rotors.

\section{Conclusions}

Recently, significant research progress has been made in structural modeling, analysis, and understanding of mistuned bladed disk vibration. Much insight to date has been gained from the use of simple lumped parameter models. However, such models are best suited to exploring fundamental issues. In the last decade, a variety of finite element-based reduced-order modeling approaches have been developed that allow bladed disk vibration to be captured with extremely compact yet accurate models relative to the parent finite element model. This makes it feasible to predict mistuned forced response for a bladed disk in the design stage and to assess the sensitivity of the system to mistuning. These reduced-order models have also been used to examine the effect of different types of mistuning patterns on forced-response amplification, to explore the use of intentional mistuning in the nominal design, and to identify blade mistuning from experimental measurements. There are still many potentially important phenomena that are typically neglected in vibration models of mistuned bladed disks, such as aerodynamic coupling and nonlinearities caused by friction and contact. Emerging research topics include combining efficient models developed in aeroelasticity and nonlinear vibration with reduced-order mistuning models, modeling the effects of blade damage, and modeling multistage systems.

\section{Acknowledgment}

The authors would like to thank Sanghum Baik and Sang Heon Song for generating the images of the tuned and mistuned mode shapes.

\section{References}

${ }^{1}$ Thomson, D. E., and Griffin, J. T., "The National Turbine Engine High Cycle Fatigue Program," Global Gas Turbine News, Vol. 39, No. 1, 1999 , pp. $14-17$.

${ }^{2}$ Whitehead, D. S., "Effect of Mistuning on the Vibration of Turbomachine Blades Induced by Wakes," Journal of Mechanical Engineering Science, Vol. 8, No. 1, 1966, pp. 15-21.

${ }^{3}$ Wagner, J. T., "Coupling of Turbomachine Blade Vibrations Through the Rotor," Journal of Engineering for Power, Vol. 89, No. 3, 1967, pp. 502-512.

${ }^{4}$ Dye, R. C. F., and Henry, T. A., "Vibration Amplitudes of Compressor Blades Resulting from Scatter in Blade Natural Frequencies," Journal of Engineering for Power, Vol. 91, No. 3, 1969, pp. 182-188.

${ }^{5}$ Ewins, D. J., "The Effects of Detuning Upon the Forced Vibrations of Bladed Disks," Journal of Sound and Vibration, Vol. 9, No. 1, 1969, pp. $65-79$.
${ }^{6}$ Ewins, D. J., "A Study of Resonance Coincidence in Bladed Discs," Journal of Mechanical Engineering Science, Vol. 12, No. 5, 1970, pp. 305-312.

${ }^{7}$ Ewins, D. J., "Vibration Characteristics of Bladed Disc Assemblies," Journal of Mechanical Engineering Science, Vol. 15, No. 3, 1973, pp. $165-186$.

${ }^{8}$ Ewins, D. J., "Vibration Modes of Mistuned Bladed Disks," Journal of Engineering for Power, Vol. 98, No. 3, 1976, pp. 349-355.

${ }^{9}$ Srinivasan, A. V., "Vibrations of Bladed-Disk Assemblies-A Selected Survey," Journal of Vibration, Acoustics, Stress and Reliability in Design, Vol. 106, No. 2, 1984, pp. 165-168.

${ }^{10}$ Srinivasan, A. V., "Flutter and Resonant Vibration Characteristics of Engine Blades," Journal of Engineering for Gas Turbines and Power, Vol. 119, No. 4, 1997, pp. 742-775.

${ }^{11}$ Slater, J. C., Minkiewicz, G. R., and Blair, A. J., "Forced Response of Bladed Disk Assemblies-A Survey," Shock and Vibration Digest, Vol. 31, No. 1, 1999, pp. 17-24

${ }^{12}$ Thomas, D. L., "Dynamics of Rotationally Periodic Structures," International Journal for Numerical Methods in Engineering, Vol. 14, No. 1, 1979, pp. 81-102.

${ }^{13}$ Whitehead, D. S., "The Maximum Factor by Which Forced Vibration of Blades Can Increase Due to Mistuning," Journal of Engineering for Gas Turbines and Power, Vol. 120, No. 1, 1998, pp. 115-119.

${ }^{14}$ Griffin, J. H., and Hoosac, T. M., "Model Development and Statistical Investigation of Turbine Blade Mistuning," Journal of Vibration, Acoustics, Stress and Reliability in Design, Vol. 106, No. 2, 1984, pp. 204-210.

${ }^{15}$ Anderson, P. W., "Absence of Diffusion in Certain Random Lattices," Physical Review, Vol. 109, No. 5, 1958, pp. 1492-1505.

${ }^{16}$ Bendiksen, O. O., "Localization Phenomena in Structural Dynamics," Chaos, Solitions and Fractals, Vol. 11, No. 10, 2000, pp. 1621-1660.

${ }^{17}$ Hodges, C. H., "Confinement of Vibration by Structural Irregularity," Journal of Sound and Vibration, Vol. 82, No. 3, 1982, pp. 411-424.

${ }^{18}$ MacBain, J. C., and Whaley, P. W., "Maximum Resonant Response of Mistuned Bladed Disks," Journal of Vibration, Acoustics, Stress, and Reliability in Design, Vol. 106, No. 2, 1984, pp. 218-223.

${ }^{19}$ Wei, S.-T., and Pierre, C., "Localization Phenomena in Mistuned Assemblies with Cyclic Symmetry, Part I: Free Vibrations," Journal of Vibration, Acoustics, Stress and Reliability in Design, Vol. 110, No. 4, 1988, pp. $429-438$.

${ }^{20}$ Wei, S.-T., and Pierre, C., "Localization Phenomena in Mistuned Assemblies with Cyclic Symmetry, Part II: Forced Vibrations," Journal of Vibration, Acoustics, Stress and Reliability in Design, Vol. 110, No. 4, 1988, pp. $439-449$.

${ }^{21}$ Wei, S.-T., and Pierre, C., "Statistical Analysis of the Forced Response of Mistuned Cyclic Assemblies," AIAA Journal, Vol. 28, No. 5, 1990, pp. 861-868.

${ }^{22}$ Óttarsson, G., and Pierre, C., "On the Effects of Interblade Coupling on the Statistics of Maximum Forced Response Amplitudes in Mistuned Bladed Disks," Proceedings of the 36th AIAA/ASME/ASCE/AHS/ASC Structures, Structural Dynamics and Materials Conference, Vol. 5, AIAA, New York, 1995, pp. 3070-3078.

${ }^{23}$ Sinha, A., and Chen, S., "A Higher Order Technique to Compute the Statistics of Forced Response of a Mistuned Bladed Disk Assembly," Journal of Sound and Vibration, Vol. 130, No. 2, 1989, pp. 207-221.

${ }^{24}$ Mignolet, M. P., and Hu, W., "Direct Prediction of the Effects of Mistuning on the Forced Response of Bladed Disks," Journal of Engineering for Gas Turbines and Power, Vol. 120, No. 3, 1998, pp. 626-634.

${ }^{25}$ Mignolet, M. P., Rivas-Guerra, A., and LaBorde, B., "Towards a Comprehensive Direct Prediction Strategy of the Effects of Mistuning on the Forced Response of Turbomachinery Blades," Aircraft Engineering and Aerospace Technology, Vol. 71, No. 5, 1999, pp. 462-469.

${ }^{26}$ Mignolet, M., Lin, C.-C., and LaBorde, B., "A Novel Limit Distribution for the Analysis of Randomly Mistuned Bladed Disks," Journal of Engineering for Gas Turbines and Power, Vol. 123, No. 2, 2001, pp. 388-394. 1958.

${ }^{27}$ Gumbel, E. J., Statistics of Extremes, Columbia Univ. Press, New York,

${ }^{28}$ Castillo, E., Extreme Value Theory in Engineering, Academic Press, Boston, 1988

${ }^{29}$ Castanier, M. P., and Pierre, C., "Consideration on the Benefits of Intentional Blade Mistuning for the Forced Response of Turbomachinery Rotors," Analysis and Design Issues for Modern Aerospace Vehicles, Vol. AD-55, edited by G. J. Simitses, American Society of Mechanical Engineers, New York, 1997, pp. 419-425.

${ }^{30}$ Bladh, R., Pierre, C., Castanier, M. P., and Kruse, M. J., "Dynamic Response Predictions for a Mistuned Industrial Turbomachinery Rotor Using Reduced-Order Modeling," Journal of Engineering for Gas Turbines and Power, Vol. 124, No. 2, 2002, pp. 311-324.

${ }^{31}$ Hurty, W. C., "Dynamic Analysis of Structural Systems Using Component Modes," AIAA Journal, Vol. 3, No. 4, 1965, pp. 678-685.

${ }^{32}$ Craig, R. R., and Bampton, M. C. C., "Coupling of Substructures for Dynamic Analyses," AIAA Journal, Vol. 6, No. 7, 1968, pp. 1313-1319. 
${ }^{33}$ Craig, R. R., Structural Dynamics: An Introduction to Computer Methods, Wiley, New York, 1981, Chap. 19.

${ }^{34}$ Irretier, H., "Spectral Analysis of Mistuned Bladed Disk Assemblies by Component Mode Synthesis," Vibrations of Bladed Disk Assemblies, edited by D. J. Ewins and A. V. Srinivasan, American Society of Mechanical Engineers, New York, 1983, pp. 115-125.

${ }^{35}$ Craig, R. R., and Chang, C.-J., "Free-Interface Methods of Substructure Coupling for Dynamic Analysis," AIAA Journal, Vol. 14, No. 11, 1976, pp. 1633-1635.

${ }^{36}$ Craig, R. R., and Chang, C.-J., "Substructure Coupling for Dynamic Analysis and Testing," NASA CR-2781, Feb. 1977.

${ }^{37}$ Zheng, Z.-C., and Wang, F.-R., "Dynamic Analysis of Blade Groups Using Component Mode Synthesis," Vibrations of Blades and Bladed Disk Assemblies, edited by R. E. Kielb and N. F. Rieger, American Society of Mechanical Engineers, New York, 1985, pp. 97-103.

${ }^{38}$ Óttarsson, G. S., "Dynamic Modeling and Vibration Analysis of Mistuned Bladed Disks," Ph.D. Dissertation, Univ. of Michigan, Ann Arbor, 1994.

${ }^{39}$ Castanier, M. P., Óttarsson, G., and Pierre, C., "A Reduced-Order Modeling Technique for Mistuned Bladed Disks," Journal of Vibration and Acoustics, Vol. 119, No. 3, 1997, pp. 439-447.

${ }^{40}$ Bladh, R., Castanier, M. P., and Pierre, C., "Reduced Order Modeling and Vibration Analysis of Mistuned Bladed Disk Assemblies with Shrouds," Journal of Engineering for Gas Turbines and Power, Vol. 121, No. 3, 1999, pp. 515-522.

${ }^{41}$ Yang, M.-T., and Griffin, J. H., "A Reduced Order Approach for the Vibration of Mistuned Bladed Disk Assemblies," Journal of Engineering for Gas Turbines and Power, Vol. 119, No. 1, 1997, pp. 161-167.

${ }^{42}$ Balmès, E., "Optimal Ritz Vectors for Component Mode Synthesis Using the Singular Value Decomposition," AIAA Journal, Vol. 34, No. 6, 1996, pp. 1256-1260.

${ }^{43}$ Balmès, E., "Use of Generalized Interface Degrees of Freedom in Component Mode Synthesis," Proceedings of the 14th International Modal Analysis Conference, Vol. 1, Society for Experimental Mechanics, Bethel, CT, 1996, pp. 204-210.

${ }^{44}$ Bourquin, F., and d'Hennezel, F., "Intrinsic Component Mode Synthesis and Plate Vibrations," Computers and Structures, Vol. 44, No. 1-2, 1992, pp. 315-324.

${ }^{45}$ Bourquin, F., and d'Hennezel, F., "Numerical Study of an Intrinsic Component Mode Synthesis Method," Computer Methods in Applied Mechanics and Engineering, Vol. 97, No. 1, 1992, pp. 49-76.

${ }^{46}$ Castanier, M. P., Tan, Y.-C., and Pierre, C., "Characteristic Constraint Modes for Component Mode Synthesis," AIAA Journal, Vol. 39, No. 6, 2001, pp. 1182-1187.

${ }^{47}$ Bladh, R., Castanier, M. P., and Pierre, C., "Component-Mode-Based Reduced Order Modeling Techniques for Mistuned Bladed Disks-Part I: Theoretical Models," Journal of Engineering for Gas Turbines and Power, Vol. 123, No. 1, 2001, pp. 89-99.

${ }^{48}$ Bladh, R., Castanier, M. P., and Pierre, C., "Component-Mode-Based Reduced Order Modeling Techniques for Mistuned Bladed Disks-Part II: Application," Journal of Engineering for Gas Turbines and Power, Vol. 123, No. 1, 2001, pp. 100-108.

${ }^{49}$ Bladh, R., Castanier, M. P., and Pierre, C., "Reduced Order Modeling Techniques for Dynamic Analysis of Mistuned Multi-Stage Turbomachinery Rotors," American Society of Mechanical Engineers, Paper 2001-GT-0276, June 2001

${ }^{50}$ Tran, D.-M., "Component Mode Synthesis Methods Using Interface Modes. Application to Structures with Cyclic Symmetry," Computers and Structures, Vol. 79, No. 2, 2001, pp. 209-222.

${ }^{51}$ Moyroud, F., Jacquet-Richardet, G., and Fransson, T., "A Comparison of Two Finite Element Reduction Techniques for Mistuned Bladed Disks," Journal of Engineering for Gas Turbines and Power, Vol. 124, No. 4, 2002, pp. 942-952.

${ }^{52}$ Yang, M.-T., and Griffin, J. H., "A Reduced-Order Model of Mistuning Using a Subset of Nominal System Modes," Journal of Engineering for Gas Turbines and Power, Vol. 123, No. 4, 2001, pp. 893-900.

${ }^{53}$ Yang, M.-T., and Griffin, J. H., "A Normalized Modal Eigenvalue Approach for Resolving Modal Interaction," Journal of Engineering for Gas Turbines and Power, Vol. 119, No. 3, 1997, pp. 647-650.

${ }^{54}$ Brewer, M. E., Castanier, M. P., and Pierre, C., "Effects of Harmonic Intentional Mistuning on the Free Response of Bladed Disks," American Society of Mechanical Engineers, Paper DETC/VIB-8012, Sept. 1999.

${ }^{55}$ Castanier, M. P., and Pierre, C., "Using Intentional Mistuning in the Design of Turbomachinery Rotors," AIAA Journal, Vol. 40, No. 10, 2002, pp. 2077-2086.

${ }^{56}$ Feiner, D., and Griffin, J., "A Fundamental Model of Mistuning for a Single Family of Modes," Journal of Turbomachinery, Vol. 124, No. 4, 2002, pp. 597-605.
${ }^{57}$ Petrov, E. P., Sanliturk, K. Y., and Ewins, D. J., "A New Method for Dynamic Analysis of Mistuned Bladed Disks Based on the Exact Relationship Between Tuned and Mistuned Systems," Journal of Engineering for Gas Turbines and Power, Vol. 124, No. 3, 2002, pp. 586-597.

${ }^{58}$ Lim, S., Bladh, R., Castanier, M. P., and Pierre, C., "A Compact, Generalized Component Mode Mistuning Representation for Modeling Bladed Disk Vibration," Proceedings of the AIAA/ASME/ASCE/AHS/ASC Structures, Structural Dynamics and Materials Conference, Vol. 2, AIAA, New York, 2003, pp. 1359-1380.

${ }^{59}$ Kaza, K. R. V., and Kielb, R. E., "Flutter and Response of a Mistuned Cascade in Incompressible Flow," AIAA Journal, Vol. 20, No. 8, 1982, pp. $1120-1127$.

${ }^{60}$ Kielb, R. E., and Kaza, K. R. V., "Effects of Structural Coupling on Mistuned Cascade Flutter and Response," Journal of Engineering for Gas Turbines and Power, Vol. 106, No. 1, 1984, pp. 17-24.

${ }^{61}$ Basu, P., and Griffin, J. H., "The Effect of Limiting Aerodynamic and Structural Coupling in Models of Mistuned Bladed Disk Vibration," Journal of Vibration, Acoustics, Stress, and Reliability in Design, Vol. 108, No. 2, 1986, pp. 132-139.

${ }^{62}$ Pierre, C., and Murthy, D. V., "Aeroelastic Modal Characteristics of Mistuned Blade Assemblies: Mode Localization and Loss of Eigenstructure," AIAA Journal, Vol. 30, No. 10, 1992, pp. 2483-2496.

${ }^{63}$ Pierre, C., Smith, T. E., and Murthy, D. V., "Localization of Aeroelastic Modes in Mistuned High-Energy Turbines," Journal of Propulsion and Power, Vol. 10, No. 3, 1994, pp. 318-328.

${ }^{64}$ Kenyon, J. A., Rabe, D. C., and Fleeter, S., "Aerodynamic Effects on Blade Vibratory Stress Variations," Journal of Propulsion and Power, Vol. 15, No. 5, 1999, pp. 675-680.

${ }^{65}$ Kielb, R. E., Feiner, D. M., Griffin, J. H., and Miyakozawa, T., "Probabilistic Analysis of Mistuned Bladed Disks and Blisks with Aerodynamic and FMM Structural Coupling," Proceedings of the 9th National Turbine Engine High Cycle Fatigue Conference, Universal Technology Corp., Dayton, OH, 2004, http://www.hcf.utcdayton.com/pages/04_proceed.html.

${ }^{66}$ Kielb, R. E., Feiner, D. M., Griffin, J. H., and Miyakozawa, T., "Flutter of Mistuned Bladed Disks and Blisks with Aerodynamic and FMM Structural Coupling," Proceedings of the 2004 ASME Turbo Expo, Vol. 6, American Society of Mechanical Engineers, New York, 2004, pp. 573-579.

${ }^{67} \mathrm{He}, \mathrm{Z}$., Epureanu, B. I., and Pierre, C., "Effects of Unsteady Aerodynamics on the Dynamic Response of Mistuned Bladed Disks," Proceedings of the Third MIT Conference on Computational Fluid and Solid Mechanics, edited by K. J. Bathe, Computational Fluid and Solid Mechanics, Elsevier, New York, 2005.

${ }^{68}$ Sinclair, G., Cormier, N., Griffin, J., and Meda, G., "Contact Stresses in Dovetail Attachments: Finite Element Modeling," Journal of Engineering for Gas Turbines and Power, Vol. 124, No. 1, 2002, pp. 182-189.

${ }^{69}$ Sinclair, G. B., and Cormier, N. G., "Contact Stresses in Dovetail Attachments: Physical Modeling," Journal of Engineering for Gas Turbines and Power, Vol. 124, No. 2, 2002, pp. 325-331.

${ }^{70}$ Legrand, M., Pierre, C., and Peseux, B., "Investigation of Rotor-Stator Interactions in Turbomachinery," Pacific Center of Thermal-Fluids Engineering, Paper ISROMAC-10-2004-102, March 2004.

${ }^{71}$ Duffy, K., Bagley, R., and Mehmed, O., "On a Self-Tuning Impact Vibration Damper for Rotating Turbomachinery," AIAA Paper 2000-3100, July 2000

${ }^{72}$ Duffy, K., Mehmed, O., and Johnson, D., "Self-Tuning Impact Dampers for Fan and Turbine Blades," Proceedings of the 6th National Turbine Engine High Cycle Fatigue Conference, Universal Technology Corp., Dayton, $\mathrm{OH}$, 2001.

${ }^{73}$ Cameron, T., and Griffin, J., "Alternating Frequency/Time Domain Method for Calculating the Steady-State Response of Nonlinear Dynamic Systems," Journal of Applied Mechanics, Vol. 56, No. 1, 1989, pp. 149-154.

${ }^{74}$ Nacivet, S., Pierre, C., Thouverez, F., and Jezequel, L., "A Dynamic Lagrangian Frequency-Time Method for the Vibration of Dry-FrictionDamped Systems," Journal of Sound and Vibration, Vol. 265, No. 1, 2003, pp. 201-219.

${ }^{75}$ Poudou, O., and Pierre, C., "Hybrid Frequency-Time Domain Methods for the Analysis of Complex Structural Systems with Dry Friction Damping," Proceedings of the AIAA/ASME/ASCE/AHS/ASC Structures, Structural Dynamics and Materials Conference, Vol. 1, AIAA, New York, 2003, pp. 111-124.

${ }^{76}$ Petrov, E. P., and Ewins, D. J., "Method for Analysis of Nonlinear Multiharmonic Vibrations of Mistuned Bladed Disks With Scatter of Contact Interface Characteristics," Journal of Turbomachinery, Vol. 127, No. 1, 2005, pp. 128-136.

${ }^{77}$ Jacquet-Richardet, G., Ferraris, G., and Rieutord, P., "Frequencies and Modes of Rotating Flexible Bladed Disc-Shaft Assemblies: A Global Cyclic Symmetry Approach," Journal of Sound and Vibration, Vol. 191, No. 5, 1996, pp. 901-915. 
${ }^{78}$ Chatelet, E., D'Ambrosio, F., and Jacquet-Richardet, G., "Toward Global Modelling Approaches for Dynamic Analyses of Rotating Assemblies of Turbomachines," Journal of Sound and Vibration, Vol. 282, No. 1-2, 2005, pp. 163-178.

${ }^{79}$ Lim, S.-H., Castanier, M. P., and Pierre, C., "Vibration Modeling of Bladed Disks Subject to Geometric Mistuning and Design Changes," Proceedings of the AIAA/ASME/ASCE/AHS/ASC Sructures, Structural Dynamics and Materials Conference, Vol. 3, AIAA, New York, 2004, pp. 1931-1950.

${ }^{80}$ Bladh, R., Castanier, M. P., and Pierre, C., "Effects of Multistage Coupling and Disk Flexibility on Mistuned Bladed Disk Dynamics," Journal of Engineering for Gas Turbines and Power, Vol. 125, No. 1, 2003, pp. $121-130$.

${ }^{81}$ Mandal, N. K., and Biswas, S., "Vibration Power Flow: A Critical Review," Shock and Vibration Digest, Vol. 37, No. 1, 2005, pp. 3-11.

${ }^{82}$ Lim, S.-H., Castanier, M. P., and Pierre, C., "Intentional Mistuning Design Space Reduction Based on Vibration Energy Flow in Bladed Disks," American Society of Mechanical Engineers, Paper GT2004-53873, June 2004.

${ }^{83}$ Baik, S., Castanier, M. P., and Pierre, C., "Assessment of Blade Mistuning Effects via Power Flow Analysis of Tuned Bladed Disks," Proceedings of the AIAA/ASME/ASCE/AHS/ASC Sructures, Structural Dynamics and Materials Conference, Vol. 4, AIAA, New York, 2005, pp. 2830-2849.

${ }^{84}$ Leissa, A. W., "On a Curve Veering Aberration," Journal of Applied Mathematics and Physics (ZAMP), Vol. 250, No. 1, 1974, pp. 99-111.

${ }^{85}$ Kuttler, J. R., and Sigillito, V. G., "On Curve Veering," Journal of Sound and Vibration, Vol. 75, No. 4, 1981, pp. 585-588.

${ }^{86}$ Perkins, N. C., and Mote, C. D., Jr., "Comments On Curve Veering in Eigenvalue Problems," Journal of Sound and Vibration, Vol. 106, No. 3, 1986, pp. 451-463.

${ }^{87}$ Gottlieb, H. P. W., "Extension of a Text-Book Problem to Curve Veering for Coupled Pendulums," Journal of Sound and Vibration, Vol. 113, No. 1, 1987, pp. 185-187.

${ }^{88}$ Pierre, C., "Mode Localization and Eigenvalue Loci Veering Phenomena in Disordered Structures," Journal of Sound and Vibration, Vol. 126, No. 3, 1988, pp. 485-502.

${ }^{89}$ Crandall, S. H., and Mroszczyk, J. W., "Conservative and Nonconservative Coupling in Dynamic Systems," Proceedings of the International Conference on Vibrations in Rotating Machinery, Insti. of Mechanical Engineers, London, 1988, pp. 567-572.

${ }^{90}$ Crandall, S. H., and Yeh, N. A., "Automatic Generation of Component Modes of Rotordynamic Substructures," Journal of Vibration, Acoustics, Stress, and Reliability in Design, Vol. 111, No. 1, 1989, pp. 6-10.

${ }^{91}$ Happawana, G., Bajaj, A., and Nwokah, O., "Singular Perturbation Perspective on Mode Localization," Journal of Sound and Vibration, Vol. 147, No. 2, 1991, pp. 361-365

${ }^{92}$ Jei, Y.-G., and Lee, C.-W., "Does Curve Veering Occur in the Eigenvalue Problem of Rotors?" Journal of Vibration and Acoustics, Vol. 114, No. 1, 1992, pp. 32-36.

${ }^{93}$ Afolabi, D., and Alabi, B., "Catastrophe Theory, Curve Veering and the Vibration of Bladed Discs," Proceedings of the Institution of Mechanical Engineers, Part C: Mechanical Engineering Science, Vol. 206, No. 2, 1992, pp. $143,144$.

${ }^{94}$ Balmes, E., "High Modal Density, Curve Veering, Localization: A Different Perspective on the Structural Response," Journal of Sound and Vibration, Vol. 161, No. 2, 1993, pp. 358-363.

${ }^{95}$ Happawana, G., Bajaj, A., and Nwokah, O., "Singular Perturbation Analysis of Eigenvalue Veering and Modal Sensitivity in Perturbed Linear Periodic Systems," Journal of Sound and Vibration, Vol. 160, No. 2, 1993, pp. 225-242.

${ }^{96}$ Afolabi, D., and Mehmed, O., "On Curve Veering and Flutter of Rotating Blades," Journal of Engineering for Gas Turbines and Power, Vol. 116, No. 3, 1994, pp. 702-708.

${ }^{97}$ Plaut, R., Murphy, K., and Virgin, L., "Curve and Surface Veering for a Braced Column," Journal of Sound and Vibration, Vol. 187, No. 5, 1995, pp. $879-885$.

${ }^{98}$ Happawana, G., Nwokah, O., Bajaj, A., and Azene, M., "Free and Forced Response of Mistuned Linear Cyclic Systems: A Singular Perturbation Approach," Journal of Sound and Vibration, Vol. 211, No. 5, 1998, pp. 761-789.

${ }^{99}$ Kenyon, J. A., "Investigation of Curve Veering Using Computational and Experimental Techniques," Proceedings of the AIAA/ASME/ASCE/ AHS/ASC Structures, Structural Dynamics and Materials Conference, Vol. 2 , AIAA, New York, 1999, pp. 1550-1558.

${ }^{100}$ Bladh, R., Castanier, M. P., and Pierre, C., "Models of Rotor Mistuning and the Prediction of Mistuned Blade Forced Response," Proceedings of the 4th National Turbine Engine High Cycle Fatigue Conference, Universal Technology Corp., Dayton, OH, 1999.

${ }^{101}$ Bhat, B., "Curve Veering: Inherent Behavior of Some Vibrating Systems," Shock and Vibration, Vol. 7, No. 4, 2000, pp. 241-249.
${ }^{102}$ Kenyon, J., and Griffin, J., "Mistuned Blade Disk Forced Response with Frequency Veering," Proceedings of the 8th National Turbine Engine High Cycle Fatigue Conference, Universal Technology Corp., Dayton, OH, 2003.

${ }^{103}$ Hussein, M. I., Pierre, C., and Castanier, M. P., "Correlation of Tuned Free Vibration Characteristics With Mistuning Sensitivity for a Bladed Disk," Proceedings of the AIAA/ASME/ASCE/AHS/ASC Structures, Structural Dynamics and Materials Conference, Vol. 2, AIAA, New York, 2003, pp. 1341-1358.

${ }^{104}$ Marugabandhu, P., and Griffin, J., "A Reduced-Order Model for Evaluating the Effect of Rotational Speed on the Natural Frequencies and Mode Shapes of Blades," Journal of Engineering for Gas Turbines and Power, Vol. 125, No. 3, 2003, pp. 772-776.

${ }^{105}$ Baik, S., Castanier, M. P., and Pierre, C., "Mistuning Sensitivity Prediction of Bladed Disks Using Eigenvalue Curve Veerings," Proceedings of the 9th National Turbine Engine High Cycle Fatigue Conference, Universal Technology Corp., Dayton, OH, 2004, http://www.hcf. utcdayton.com/pages/04_proceed.html.

${ }^{106}$ Kenyon, J., Griffin, J., and Kim, N., "Frequency Veering Effects on Mistuned Bladed Disk Forced Response," Journal of Propulsion and Power, Vol. 20, No. 5, 2004, pp. 863-870.

${ }^{107}$ Claassen, R. W., and Thorne, C. J., "Vibrations of a Rectangular Cantilever Plate," Journal of Aerospace Science, Vol. 29, No. 11, 1962, pp. 1300-1305.

${ }^{108}$ Thom, R., Structural Stability and Morphogenesis: An Outline of a General Theory of Models, W. A. Benjamin, Reading, MA, 1975.

${ }^{109}$ Zeeman, E. C., Catastrophe Theory: Selected Papers, 1972-1977, Addison Wesley Longman, Reading, MA, 1977.

${ }^{110}$ Slater, J. C., and Blair, A. J., "Minimizing Sensitivity of Bladed Disks to Mistuning," Proceedings of the 16th International Modal Analysis Conference, Vol. 1, Society for Experimental Mechanics, Bethel, CT, 1998, pp. 284-290.

${ }^{111}$ Crawley, E. F., and Hall, K. C., "Optimization and Mechanisms of Mistuning in Cascades," Journal of Engineering for Gas Turbines and Power, Vol. 107, No. 2, 1985, pp. 418-426.

${ }^{112}$ Nissim, E., "Optimization of Cascade Blade Mistuning, Part I: Equations of Motion and Basic Inherent Properties," AIAA Journal, Vol. 23, No. 8 , 1985, pp. 1213-1222.

${ }^{113}$ Nissim, E., and Haftka, R. T., "Optimization of Cascade Blade Mistuning, Part II: Global Optimum and Numerical Optimization,” AIAA Journal, Vol. 23, No. 9, 1985, pp. 1402-1410.

${ }^{114}$ Shapiro, B., and Coller, B., "Characterizing Optimal Mistuning by Symmetry Arguments: A General Framework Applied to a Dynamic Flutter Model," Proceedings of the IEEE Conference on Control Applications, Inst. of Electrical and Electronics Engineers, New York, 1997, pp. 901-906.

${ }^{115}$ Sinha, A., "Computation of the Maximum Amplitude of a Mistuned Bladed Disk Assembly via Infinity Norm," Analysis and Design Issues for Modern Aerospace Vehicles, Vol. AD-55, edited by G. J. Simitses, American Society of Mechanical Engineers, New York, 1997, pp. 427-432.

${ }^{116}$ Petrov, E. P., Vitali, R., and Haftka, R. T., "Optimization of Mistuned Bladed Disks Using Gradient-based Response Surface Approximations," Proceedings of the 41 st AIAA/ASME/ASCE/AHS/ASC Structures, Structural Dynamics, and Materials Conference, Vol. 1, AIAA, Reston, VA, 2000, pp. 1129-1139.

${ }^{117}$ Rotea, M., and D'Amato, F., "New Tools for Analysis and Optimization of Mistuned Bladed Disks," AIAA Paper 2002-4081, July 2002.

${ }^{118}$ Petrov, E. P., and Ewins, D. J., "Analysis of the Worst Mistuning Patterns in Bladed Disk Assemblies," Journal of Turbomachinery, Vol. 125, No. 4, 2003, pp. 623-631

${ }^{119}$ Yiu, H., and Ewins, D. J., "Dependence on Blade Arrangements of Mistuned Bladed Disc of the Optimal and Critical Resonant Responses," Proceedings of the 6th International Symposium on Transport Phenomena and Dynamics of Rotating Machinery, Vol. 1, edited by D. C. Han, S. T. Ro, and J. H. Kim, Pacific Center of Thermal-Fluids Engineering, Kihei, HI, 1996, pp. 237-251

${ }^{120}$ Petrov, E. P., and Ewins, D. J., "Search for the Best Blade Arrangement in a Mistuned Bladed Disc Assembly," Proceedings of the 7th National Turbine Engine High Cycle Fatigue Conference, Universal Technology Corp., Dayton, OH, 2002.

${ }^{121}$ El-Bayoumy, L. E., and Srinivasan, A. V., "Influence of Mistuning on Rotor-Blade Vibrations," AIAA Journal, Vol. 13, No. 4, 1975, pp. 460-464.

${ }^{122}$ Ewins, D. J., "Further Studies of Bladed Disc Vibration: Effects of Packeting," Proceedings of the International Conference on Vibrations in Rotating Machinery, Inst. of Mechanical Engineers, London, 1980, pp. 97-102.

${ }^{123}$ Ewins, D. J., and Imregun, M., "Vibration Modes of Packeted Bladed Disks," Journal of Vibration, Acoustics, Stress, and Reliability in Design, Vol. 106, No. 2, 1984, pp. 175-180.

${ }^{124}$ Rzadkowski, R., "Transient Nozzle Excitation of Mistuned Bladed Discs," Journal of Sound and Vibration, Vol. 190, No. 4, 1996, pp. 629-643. 
${ }^{125}$ Castanier, M. P., and Pierre, C., "Investigation of the Combined Effects of Intentional and Random Mistuning on the Forced Response of Bladed Disks," AIAA Paper 98-3720, July 1998.

${ }^{126}$ Kenyon, J., Griffin, J., and Feiner, D., "Maximum Bladed Disk Forced Response from Distortion of a Structural Mode," Journal of Turbomachinery, Vol. 125, No. 2, 2003, pp. 352-363.

${ }^{127}$ Jones, K., and Cross, C., "On Antiresonance in the Forced Response of Mistuned Bladed Disks," Proceedings of IMAC-XX: A Conference on Structural Dynamics, Vol. 1, Society for Experimental Mechanics, Bethel, CT, 2002, pp. 491-498.

${ }^{128}$ Kenyon, J. A., and Griffin, J. H., "Forced Response of Turbine Engine Bladed Disks and Sensitivity to Harmonic Mistuning," Journal of Engineering for Gas Turbines and Power, Vol. 125, No. 1, 2003, pp. 113-120.

${ }^{129}$ Kenyon, J., and Griffin, J., "Experimental Demonstration of Maximum Mistuned Bladed Disk Forced Response," Journal of Turbomachinery, Vol. 125, No. 4, 2003, pp. 673-681.

${ }^{130}$ Jones, K., and O'Hara, R., "Linear Intentional Mistuning for Reduction of Bladed Disk Forced Response," Proceedings of the 8th National Turbine Engine High Cycle Fatigue Conference, Universal Technology Corp., Dayton, OH, 2003.

${ }^{131}$ Choi, B.-K., Lentz, J., Rivas-Guerra, A. J., and Mignolet, M. P., "Optimization of Intentional Mistuning Patterns for the Reduction of the Forced Response Effects of Unintentional Mistuning: Formulation and Assessment," Journal of Engineering for Gas Turbines and Power, Vol. 125, No. 1, 2003, pp. 131-140.

${ }^{132}$ Rivas-Guerra, A. J., and Mignolet, M. P., "Maximum Amplification of Blade Response due to Mistuning: Localization and Mode Shape Aspects of the Worst Disks," Journal of Turbomachinery, Vol. 125, No. 3, 2003, pp. 442-454.

${ }^{133}$ Xiao, B., Rivas-Guerra, A. J., and Mignolet, M. P., "Maximum Amplification of Blade Response due to Mistuning in Multi-Degree-of-Freedom Blade Models," Proceedings of the 2004 ASME Turbo Expo, Vol. 6, American Society of Mechanical Engineers, New York, June 2004, pp. 427-438.

${ }^{134}$ Hou, J., and Cross, C., "Minimizing Blade Dynamic Response in a Bladed Disk Through Design Optimization," AIAA Journal, Vol. 43, No. 2, 2005, pp. 406-412.

${ }^{135}$ Pierre, C., Judge, J., Ceccio, S. L., and Castanier, M. P., "Experimental Investigation of the Effects of Random and Intentional Mistuning on the Vibration of Bladed Disks," Proceedings of the 7th National Turbine Engine High Cycle Fatigue Conference, Universal Technology Corp., Dayton, OH, 2002.

${ }^{136}$ Mignolet, M. P., and Lin, C.-C., "Identification of Structural Parameters in Mistuned Bladed Disks," Journal of Vibration and Acoustics, Vol. 119,
No. 3, 1997, pp. 428-438

${ }^{137}$ Mignolet, M., Rivas-Guerra, A., and Delor, J., "Identification of Mistuning Characteristics of Bladed Disks from Free Response Data-Part I," Journal of Engineering for Gas Turbines and Power, Vol. 123, No. 2, 2001, pp. 395-403.

${ }^{138}$ Rivas-Guerra, A., Mignolet, M., and Delor, J., "Identification of Mistuning Characterics of Bladed Disks from Free Response Data-Part II," Journal of Engineering for Gas Turbines and Power, Vol. 123, No. 2, 2001, pp. 404-411.

${ }^{139}$ Judge, J., Pierre, C., and Ceccio, S. L., "Identification of Mistuning in Blisks," Proceedings of the 6th National Turbine Engine High Cycle Fatigue Conference, Universal Technology Corp., Dayton, OH, 2001.

${ }^{140}$ Judge, J., Pierre, C., and Ceccio, S. L., "Experimental Validation of Mistuning Identification and Vibration Predictions in Bladed Disks," Proceedings of the CEAS/AAIA/AIAE International Forum on Aeroelasticity and Structural Dynamics, Madrid, Spain, Vol. 2, 2001, pp. 89-98.

${ }^{141}$ Judge, J. A., Pierre, C., and Ceccio, S. L., "Mistuning Identification in Bladed Disks," Proceedings of the International Conference on Structural Dynamics Modelling, edited by N. M. M. Maia, J. M. M. Silva, and A. M. R. Ribeiro, Instituto Superior Técnico, Lisbon, Portugal, 2002.

${ }^{142}$ Feiner, D., and Griffin, J., "Mistuning Identification of Bladed Disks Using a Fundamental Mistuning Model—Part I: Theory," Journal of Turbomachinery, Vol. 126, No. 1, 2004, pp. 150-158.

${ }^{143}$ Feiner, D., and Griffin, J., "Mistuning Identification of Bladed Disks Using a Fundamental Mistuning Model-Part II: Application," Journal of Turbomachinery, Vol. 126, No. 1, 2004, pp. 159-165.

${ }^{144}$ Lim, S., Castanier, M. P., and Pierre, C., "Mistuning Identification and Reduced-Order Model Updating for Bladed Disks Based on a Component Mode Mistuning Technique," Proceedings of the 9th National Turbine Engine High Cycle Fatigue Conference, Universal Technology Corp., Dayton, $\mathrm{OH}, 2004$, http://www.hcf.utcdayton.com/pages/04_proceed.html.

${ }^{145}$ Lim, S.-H., "Dynamic Analysis and Design Strategies for Mistuned Bladed Disks," Ph.D. Dissertation, Univ. of Michigan, Ann Arbor, 2005.

${ }^{146}$ Judge, J. A., "Experimental Investigations of the Effects of Mistuning on Bladed Disk Dynamics," Ph.D. Dissertation, Univ. of Michigan, Ann Arbor, 2002

${ }^{147}$ Lin, C.-C., and Mignolet, M., "Effects of Damping and Damping Mistuning on the Forced Vibration Response of Bladed Disks," Journal of Sound and Vibration, Vol. 193, No. 2, 1996, pp. 525-543.

${ }^{148}$ Crawley, E. F., and Mokadam, D. R., "Stagger Angle Dependence of Inertial and Elastic Coupling in Bladed Disks," Journal of Vibration, Acoustics, Stress, and Reliability in Design, Vol. 104, No. 2, 1984, pp. 181-188. 